\title{
LA INFLUENCIA DEL CEDH Y DE LA JURISPRUDENCIA DEL TEDH EN EL ORDENAMIENTO CONSTITUCIONAL ITALIANO ${ }^{1}$
}

\author{
ROBERTO ROMBOLI \\ Profesor Ordinario de Derecho Constitucional \\ Universidad de Pisa
}

\section{EL CEDH EN EL SISTEMA DE FUENTES DEL ORDENAMIENTO ITALIANO Y LA AUSENCIA DE CONTACTO ENTRE LA CORTE CONSTITUCIONAL Y EL TEDH}

En Italia la reflexión sobre el significado y la eficacia del Convenio Europeo de Derechos Humanos (en adelante, CEDH) y, por consiguiente, de la jurisprudencia del Tribunal Europeo de Derechos Humanos (en adelante, TEDH) se basó en un primer momento principalmente en la ubicación del $\mathrm{CEDH}$ en el sistema de fuentes del derecho y, por tanto, en aspectos esencialmente de carácter formal.

El CEDH fue recibido en Italia mediante ley de 4 de agosto de 1955 (n. ${ }^{\circ} 848$ ), según el modelo de ratificación y ejecución de Tratados Internacionales, y no se consideró necesario proceder a una revisión de la Constitución con la finalidad de dar al CEDH una cobertura constitucional ${ }^{2}$.

Por el contrario, encuentra la aplicación el consolidado principio según el cual las disposiciones de un Tratado asumen en el ámbito del sistema de fuentes la misma ubicación del acto a través del cual aquéllas son introducidas en el ordenamiento estatal. Por consiguiente, de ello se deriva, siguiendo dicha regla, que las disposiciones del CEDH tienen en el ordenamiento italiano la misma ubicación y fuerza que la ley, con todo lo que ello significa.

La situación viene a plantearse en términos parcialmente diversos (al menos desde el punto de vista sustantivo) cuando los tratados tengan como objeto, como en nuestro caso, el reconocimiento de las libertades fundamentales y los derechos humanos.

1 Traducción de Maria Garrote, Profesora Contratada Doctora interina de Derecho Constitucional, UCM.

2 La ley constitucional de 23 de noviembre de 1999 (n..$^{\circ}$ ), por la que se modifica el art. 111 de la Constitución italiana, introduce los principios del debido proceso mediante una formulación que recoge, en algunos puntos incluso literalmente, el contenido del art. 6 del CEDH, lo que demuestra que no se consideraba suficiente la garantía derivada de estar dichos principios contenidos en el acto convencional y aplicables como tales en Italia. 
En esta hipótesis parece evidente, de hecho, que nos encontramos frente a un clara disociación entre la forma y la sustancia, es decir, frente a un acto formalmente con fuerza de ley ordinaria (por tanto modificable o derogable mediante otro acto del mismo rango e inidóneo para ser planteado como parámetro en un juicio de constitucionalidad de las leyes), pero que tiene además un contenido seguramente de naturaleza constitucional, por cuanto afecta a materia típicamente constitucional, como se deduce del elenco de derechos reconocidos (derecho a la vida, a la libertad personal, a la seguridad, a la libertad de pensamiento, a un proceso justo, prohibición de tortura, prohibición de esclavitud).

Todos (o casi todos) los derechos y libertades previstos en el CEDH encuentran reconocimiento o estrechas analogías en las previsiones recogidas expresamente a nivel constitucional (tanto es así, que sobre esta base se ha elaborado la teoría de la supuesta «inutilidad» de una referencia directa a la normativa convencional).

La mencionada disociación produce algunos inconvenientes, para cuya superación y con la finalidad de conciliar el valor formal con el valor material de las libertades sancionadas en el CEDH, se han ido elaborando en Italia toda una serie de reconstrucciones tendentes a proporcionar a las disposiciones del CEDH de una «cobertura» constitucional.

Entre las diferentes tesis sostenidas para dotar de una «cobertura» constitucional al $\mathrm{CEDH}$, algunas hacen referencia al artículo 2 de la Constitución en la parte en la que se reconocen y garantizan «los derechos inviolables de la persona», el cual proporcionaría una cobertura constitucional a los Tratados sobre derechos humanos, desde el momento que los derechos en ellos previstos deberían estar incluidos en la noción de «derechos inviolables» del artículo 2 de la Constitución ${ }^{3}$.

Sin embargo, según otras posturas diferentes, la «cobertura» constitucional de las disposiciones del CEDH debería provenir del artículo 10.1 de la Constitución, en base al cual el ordenamiento jurídico italiano integra las normas de derecho internacional generalmente reconocidas. A juicio de algunos, de hecho, este artículo debería servir de «convertidor automático», no sólo de las normas internacionales de tipo consuetudinario, sino también de las que tienen origen convencional.

La referencia a esta misma disposición constitucional es también la base de otra tesis, más elaborada, según la cual el tratado que introduce el $\mathrm{CEDH}$, además de la aparente naturaleza convencional tiene en realidad una naturaleza consuetudinaria, al referirse a un patrimonio común de valores inherente a la protección de la dignidad humana.

Otros, en cambio, invocan el artículo 11 de la Constitución en la parte en la que permite, en condiciones de igualdad con otros Estados, limitaciones en la propia soberanía, siempre que sean necesarias para la creación de un ordenamiento que asegure la paz y la justicia entre las naciones, finalidad que sería precisamente la perseguida por los Tratados internacionales sobre derechos humanos. Como puede comprobarse, el razonamiento es análogo al que se ha desarrollado para proporcionar un «paraguas de protección» de nivel constitucional al ordenamiento comunitario.

3 Más allá de la clara contraposición —-más aparente que real en cuanto a los resultados concretos a los que llegan las diferentes posturas - entre quienes ven en la mencionada disposición constitucional y en la referencia a derechos inviolables un supuesto abierto a los denominados nuevos derechos, y los que consideran que la misma se limita a los derechos mencionados en los diferentes artículos de la Constitución, no parece que sea posible excluir en este caso la necesidad de comprobar si determinados derechos y libertades contenidos en el CEDH pueden ser subsumidos en la noción de «derechos inviolables». 
Finalmente, otras tesis han considerado que es posible reforzar la posición del $\mathrm{CEDH}$ en el ordenamiento italiano mediante la recepción del Convenio en el ámbito del derecho comunitario, de modo que se podría recurrir a los principios e instrumentos que han permitido afirmar la primacía del derecho comunitario sobre el derecho interno.

En una decisión de la Corte Constitucional, y más precisamente en un obiter dictum de la misma, se avanzó una reconstrucción de las relaciones entre la ley ordinaria y el $\mathrm{CEDH}$ con el fin de asegurar a la ley n. ${ }^{\circ} 848$ de 1955 una posición particular y poder así diferenciarla de otras leyes. En esa ocasión, la Corte, a propósito del art. $6 \mathrm{CEDH}$ sostiene que tal Tratado, a pesar de haber sido incorporado al ordenamiento italiano con fuerza de ley, no puede considerarse derogado por leyes posteriores del mismo rango "porque se trata de una norma que deriva de una fuente proveniente de una competencia atípica y, como tal, no es susceptible de derogación o modificación por parte de disposiciones de ley ordinaria» (sent. 10/1993). Esta afirmación, bastante innovadora con respecto a la jurisprudencia anterior, sin embargo, no ha tenido repercusión posterior y ha permanecido completamente aislada.

En otra ocasión —en relación con una cuestión de constitucionalidad elevada por el juez, también con referencia al artículo $6 \mathrm{CEDH}$ cuya violación habría supuesto, a su juicio, una lesión del artículo 11 de la Constitución- la Corte constitucional sostuvo que, independientemente del valor atribuido a las normas convencionales, que no se colocan por sí mismas en un nivel constitucional, es manifiesto que los derechos humanos, garantizados también por Convenciones universales o regionales suscritas por Italia, encuentran expresión y no menos garantía en la Constitución: no sólo por el valor que se atribuye al reconocimiento de los derechos inviolables de la persona en el art. 2 de la Constitución, considerados por la conciencia contemporánea como coesenciales a la dignidad de la persona, sino también porque además de la coincidencia en el catálogo de tales derechos, las diferentes fórmulas que los expresan se integran completándose recíprocamente en la interpretación. Eso es precisamente lo que sucede con el derecho a obtener la tutela judicial efectiva de derechos e intereses, garantizado en el artículo 24 de la Constitución, que implica una duración razonable del proceso para que la decisión jurisdiccional, a la cual está orientada la acción, promovida para tutelar el derecho asegure la protección eficaz del mismo y, en definitiva, la realización de la justicia (sent. 388/1999).

La disociación antes mencionada entre los aspectos formales y de contenido de los Tratados de derechos humanos ha influido inevitablemente en la posición adoptada por la jurisprudencia constitucional en este sentido, que, en este punto, no parecía completamente lineal en la relación entre las premisas y el examen concreto de las cuestiones de constitucionalidad elevadas sobre las disposiciones del CEDH.

La Corte constitucional, a través de una jurisprudencia constante, a excepción de la mencionada sentencia 10/1993, ha sostenido siempre, con respecto al CEDH, que los Tratados internacionales vienen a asumir en el ordenamiento la misma posición del acto que los ejecuta, por lo que «cuando la ejecución acaece mediante ley ordinaria, aquéllos adquieren la fuerza y el rango de ley ordinaria que puede ser derogada o modificada por una ley ordinaria posterior» (sent. 323/1989), excluyendo expresamente la posibilidad de reconocer a los mismos un rango constitucional o en todo caso superior respecto al de la ley ordinaria.

Incluso, después de un acontecimiento de extraordinaria importancia para el sistema de tutela de los derechos reconocidos en el $\mathrm{CEDH}$, como es la introducción del recurso 
directo del ciudadano ante la Corte de Estrasburgo ${ }^{4}$, las referencias al CEDH en los juicios de ante la Corte constitucional siguen siendo extremadamente raras y su incidencia en la resolución de las cuestiones de constitucionalidad escasa, fundándose casi exclusivamente en la conformidad de los actos legislativos con los parámetros constitucionales.

Aunque la Corte constitucional haya iniciado su funcionamiento en 1953 y el TEDH lo haya hecho tres años después, y pese a que la primera haya acogido una noción «abierta» de «derechos inviolables» reconocidos en el art. 2 de la Constitución, ambas Cortes, como se ha señalado, ${ }^{5}$ se han ignorado recíprocamente.

La relación con el CEDH y el TEDH ha sido mayormente promovida por los jueces ordinarios, y en particular, por la suprema Corte de Casación, cuyos magistrados en varias ocasiones han elevado cuestiones de constitucionalidad denunciando también la supuesta violación de las disposiciones del CEDH.

La Corte constitucional ha tenido, como se ha dicho, una posición formalista sobre la ubicación del CEDH en el sistema de fuentes, por lo que las referencias al CEDH en el proceso constitucional asumen como mucho un rol de «reforzar» la denuncia del parámetro constitucional o de integración del mismo con fines interpretativos en el ánimo de sugerir una lectura amplia de la letra de la Constitución.

Por otra parte, dado que no se pueden plantear las normas convencionales como parámetros en un proceso de constitucionalidad, en la hipótesis de una eventual contradicción entre la ley nacional y el CEDH los jueces ordinarios han procedido en algún caso a una, si bien criticada, inaplicación de la ley y a la aplicación directa del Convenio ${ }^{6}$.

\section{LA REFORMA CONSTITUCIONAL DE 2001 Y LA INTRODUCCIÓN DEL COMPROMISO DEL ESTADO ITALIANO DE CUMPLIR CON LAS OBLIGACIONES INTERNACIONALES (ART. 117.1 CI). LAS HISTÓRICAS «SENTENCIAS GEMELAS» DE 2007 DE LA CORTE CONSTITUCIONAL Y EL RECONOCIMIENTO DE LA CEDH COMO PARÁMETRO CONSTITUCIONAL A TRAVÉS DE LA TÉCNICA DE LA NORMA INTERPUESTA}

En 2001 se llevó a cabo la más amplia reforma constitucional ${ }^{7}$ que tenía como objeto el reparto de competencias entre el Estado y las regiones (Título V de la parte segunda de la Constitución).

4 Introducido con la aprobación del protocolo 11, firmado en Estrasburgo el 11 de mayo de 1994 y ratificado en Italia mediante la ley de 28 de agosto de 1997, n. $^{\circ} 296$.

5 Lamarque E., «La Convenzione europea dei diritti dell'uomo a uso dei giudici italiani», en Padula C. (ed.), La Corte europea dei diritti dell'uomo. Quarto grado di giudizio o seconda Corte costituzionale?, Napoli, E.S., 2016, p. 139 y ss.

6 El reconocimiento al juez nacional de la posibilidad de referirse directamente al Convenio y de darle aplicación directa asume evidentemente una notable importancia, sea por la tutela efectiva de los derechos, sea por la formación cultural de la magistratura y sobre todo por la penetración, dentro del ordenamiento estatal, de los principios expresados en el Convenio. En Italia los jueces ordinarios, aunque en un primer momento se orientaron a reconocer un valor programático a las disposiciones del $\mathrm{CEDH}$, sucesivamente han afirmado la naturaleza de fuente del CEDH y su aplicación directa por parte del juez.

7 Otras reformas, también muy amplias del texto constitucional fueron aprobadas por el Parlamento con mayoría absoluta en 2005 y en 2016, pero fueron rechazadas por el voto popular manifestado a través del referéndum constitucional. 
La finalidad de la reforma era remodelar las relaciones entre el Estado y las regiones en el sentido de aumentar la autonomía de estas últimas y perseguir una igualdad tendencial entre los dos sujetos institucionales.

En concreto, y a lo que interesa a nuestro objeto, se modificó el art. 117 de la Constitución introduciendo en el primer apartado una nueva disposición según la cual «la potestad legislativa es ejercida por el Estado y las regiones en el respeto a la Constitución, así como a los compromisos derivados del ordenamiento comunitario y de las obligaciones internacionales».

Si la finalidad más evidente de la nueva previsión parece ser la de fijar un principio de «igualdad de armas» entre el Estado y las regiones, en realidad hasta ahora no se ha dejado de poner de relieve cómo el aspecto más importante y más innovador fue sin embargo la previsión relativa al deber el Estado (y de las regiones) de respetar no sólo las obligaciones derivadas del ordenamiento comunitario - ya despojado de la cobertura constitucional del art. 11 de la Constitución — sino también las obligaciones internacionales.

Aunque la disposición se refiera genéricamente y sin distinciones a todos los tratados internacionales, el pensamiento de muchos se dirigió al tratado de adhesión al CEDH y a las obligaciones que con el mismo asumía el Estado italiano y por eso podemos considerar que una disposición así habría encontrado un mejor acomodo entre los principios generales y los de integración previstos en los arts. 10 y 11 de la Constitución, más que en la parte relativa al ordenamiento de las regiones y los entes locales.

En los años sucesivos a la referida reforma, la Corte constitucional parece ignorar la innovación y las consecuencias derivadas del nuevo texto del art. 117.1 de la Constitución y de hecho, después de cuatro años de la aprobación de la misma, el juez constitucional en una ocasión responde secamente que «el artículo 8 del CEDH no asume el valor de norma parámetro» (sent. 464/2005).

La posición asumida al respecto por la jurisprudencia constitucional ha sido objeto desde hace tiempo de observaciones críticas por parte de la doctrina, que en buena medida no ha dejado de subrayar cómo esta actitud llevaría inevitablemente a una postura de cierre frente al otro Tribunal, impidiendo la instauración de un diálogo que habría podido ser bastante provechoso para una mejor y más completa tutela de los derechos fundamentales, en buena parte homogéneos, presentes en las dos Cartas constitucionales.

La situación italiana ha sido definida como «particularmente penosa» en consideración a la ubicación del CEDH en el sistema de fuentes y al hecho de que la jurisprudencia del TEDH fuese largamente ignorada por la Corte constitucional, la cual mostraba una resistencia, inexistente en otros ámbitos, a considerar que «la jurisprudencia derivada de la interpretación judicial por parte del juez competente oriente necesariamente la interpretación del texto normativo que está en el origen, por encima del resto de jueces» ${ }^{8}$.

Se ha señalado a la jurisprudencia de la Corte constitucional como una de las razones que habían inducido a los jueces ordinarios a proceder directamente a inaplicar las leyes y actos con fuerza de ley nacionales por contraste con las disposiciones del CEDH y, desde muchas partes, se ha señalado como una de las posibles soluciones la revalorización

8 Zagrebelsky V., Corte, Convenzione europea dei diritti dell'uomo e sistema europeo di protezione dei diritti fondamentali, en Foro it., 2006, V, p. 357 y ss. 
del «nuevo» art. 117.1 de la Constitución, cuando se afirma la necesidad de que la ley respete las obligaciones internacionales?.

Después de seis años de la aprobación de la reforma constitucional, la Corte constitucional pronuncia dos decisiones (definidas entonces y ahora unánimemente conocidas como las «sentencias gemelas») con las cuales introduce un cambio fundamental en su propia jurisprudencia, abriendo de esta manera una nueva fase riquísima de perspectivas para el rol del TEDH en los procesos constitucionales y, consiguientemente, para las relaciones entre la Corte constitucional y el $\mathrm{TEDH}^{10}$.

Los pronunciamientos (sent. 348 y 349/2007) pueden considerarse como verdaderamente de relevancia histórica por los casos que les seguirán, por lo que parece absolutamente necesario sintetizar en cinco puntos las importantes afirmaciones contenidas en las dos sentencias.

El primero es la afirmación dirigida a los jueces y a la mencionada tendencia de algunos de ellos a inaplicar las leyes consideradas contrarias a la normativa del CEDH. La Corte afirma «ser llamada a clarificar dicha problemática normativa e institucional, que tiene relevantes implicaciones prácticas en la praxis cotidiana de los operadores del derecho» y lo hace separando totalmente los efectos del derecho comunitario y el del CEDH en nuestro ordenamiento, para lo cual se confirma la jurisprudencia según la cual no es posible hacer referencia al artículo 10.1 de la Constitución para operar a través del mecanismo de la norma interpuesta, ya que dicha disposición constitucional se refiere sólo a las normas consuetudinarias y no a las contractuales, ni tampoco, de manera indirecta al artículo 11 de la Constitución "por efecto de la calificación por parte del Tribunal de Justicia de la Unión Europa de los derechos fundamentales objeto del CEDH como principios generales del ordenamiento comunitario».

En base a ello, la Corte concluye que «el juez ordinario no tiene, por tanto, el poder de inaplicar la norma legislativa ordinaria considerada contraria a una norma del CEDH, ya que la patente incompatibilidad entre ambas se presenta como una cuestión de

9 No vamos tampoco a silenciar los riesgos que, para el papel de la Corte constitucional, se derivan de una equiparación del derecho del CEDH al derecho comunitario y, casi anticipando la posición después asumida por la Corte en las «sentencias gemelas», se ha sostenido que «el reconocimiento de que el CEDH y el propio sistema de tutela de derechos se coloca en un nivel tal que dichas normas hacen de parámetro de constitucionalidad de las normas ordinarias en conflicto con ellos tendría la ventaja de ser coherente con el sistema constitucional italiano, que atribuye a la Corte constitucional la tutela de lodo derechos fundamentales y la competencia para expulsar del ordenamiento, con efecto erga omnes, las normas ordinarias que los infrinjan», concluyendo (y casi advirtiendo) que «si una declaración adecuada no puede venir de la Corte constitucional entonces la mirada debería dirigirse al legislador, con la esperanza de que el tema aquí afrontado encuentre en el Parlamento la atención que requiere» (V. Zagrabelsky)

10 Recientemente, uno de los magistrados, ponente de una de las dos sentencias, Gaetano Silvestri, ha recordado que a la Corte le interesaba principalmente poner fin a la inaplicación de las leyes nacionales efectuada en solitario por los jueces y que las «sentencias gemelas» nacen de una incómoda condena a Italia del Tribunal de Estrasburgo (caso Scordino) sobre la determinación de las indemnizaciones en caso de expropiaciones por casusa de utilidad pública. Silvestri recuerda que se planteó la alternativa entre revalorizar la posición expresada en la sentencia 10/1993 o basarse en el nuevo art. 117.1 de la Constitución. La necesidad de ponderar la posición manifestada por el TEDH, en favor de un criterio referido al valor de mercado, con la previsión de la función social de la propiedad proclamada en el art. 42 de la Constitución, condujo a optar por una política de «pequeños pasos» y por tanto inclinarse por la segunda de las alternativas indicadas, proporcionando una interpretación de la disposición constitucional adecuada a la contextualización espacio-tiempo del CEDH, en el ámbito de Europa y de la época contemporánea. Silvestri G., «Considerazioni conclusive», en Osservatorio sulle fonti, n. ${ }^{\circ}$ 1/2018 (www. osservatoriosullefonti.it). 
legitimidad constitucional, por una eventual violación del art. 117.1 de la Constitución, de exclusiva competencia del Juez de las leyes».

El segundo se refiere a la revalorización por parte de la Corte — como hasta ahora nunca había hecho, pese a haber tenido muchas oportunidades_- del nuevo art. 117.1 de la Constitución, el cual «ha colmado una laguna y, en armonía con las Constituciones de otros países europeos, se conecta, prescindiendo de su ubicación sistemática en la Carta constitucional, con el marco de principios que expresamente ya garantizaban a nivel primario la observancia de determinadas obligaciones internacionales asumidas por el Estado».

La referencia al artículo 117.1 de la Constitución permite a la Corte introducir una ulterior hipótesis, además de las conocidas, de posible utilización de la técnica de la denominada norma interpuesta, en base a la cual una ley puede ser declarada inconstitucional también cuando directamente contradice una ley o acto con fuerza de ley, pero que podría decirse que, dada la estrecha vinculación entre ésta última y un precepto constitucional, la contradicción se produce, aunque sea indirectamente, con el propio precepto constitucional (como en el caso más claro de violación por parte de un decreto legislativo de una disposición de la ley de delegación que contiene un principio o criterio objetivo).

El tercero se refiere a la puntualización del orden de colocación del CEDH en nuestro sistema de fuentes y las consecuencias que se derivan para el proceso constitucional. La Corte señala que la calificación de norma interpuesta no significa que a las normas del $\mathrm{CEDH}$ se les atribuya la fuerza de las normas constitucionales, conservando sin embargo la naturaleza de fuente primaria y como tal sujeta al control de constitucionalidad, el cual, a diferencia de lo que ocurre con el derecho comunitario, puede y debe desarrollarse respecto de cada disposición constitucional y no sólo respecto de los principios y derechos fundamentales (denominados contra-límites). Por tanto, para evitar la paradoja de expulsar una ley por no respetar otra ley a su vez inconstitucional, la fuente que hace de norma interpuesta (norma del CEDH como ha sido introducida en nuestro ordenamiento) debe ser previamente sometida a control de constitucionalidad.

De esta manera las normas contenidas en el CEDH pueden actualmente adoptar el papel o de parámetro o de objeto en el juicio de constitucionalidad de las leyes, lo que repercute a su vez en el deber de interpretación conforme por parte de los jueces, de acuerdo con lo expresamente indicado por la Corte con respecto a la normativa CEDH, tal como surge en relación con la Constitución.

En el primer caso, de hecho, el juez, para evitar «conformarse» con un derecho inconstitucional, debe cuestionarse primero la conformidad de la disposición del CEDH con la Constitución y solo después de haber resuelto la misma en sentido positivo proceder a la segunda verificación, consistente en la viabilidad de una lectura de la ley de conformidad con el principio del CEDH.

El cuarto se refiere a la revalorización que la Corte constitucional pretendía hacer de la jurisprudencia del TEDH, con toda probabilidad persiguiendo una duplicidad de fines: la de evitar conflictos jurisprudenciales con la Corte Europea y la de reconocer la necesidad de que disposiciones sustancialmente constitucionales - tales como el $\mathrm{CEDH}$ - , que tienen una aplicación supranacional tengan, en la medida de lo posible, la misma interpretación en los diferentes Estados que han firmado el Convenio.

Por esta razón, la Corte constitucional tiende a destacar la «especialidad» del Tratado en cuestión con respecto a todos los demás, habiendo éste confiado la función de interpretar las reglas del CEDH a un juez único y específico, precisamente el TEDH, y 
saca de ello la consecuencia de que al verificar o referirse a la normativa del CEDH, ésta será asumida con el significado que le atribuye «su» Juez.

Para algunos ello parecía «una llamativa limitación» de la soberanía estatal, al ver una especie de equiparación con la eficacia ahora pacíficamente reconocida de las sentencias interpretativas del derecho comunitario del Tribunal de Justicia, y subrayando también, que en caso del Tribunal de Estrasburgo se trata de una jurisprudencia estrechamente vinculada a los casos concretos examinados y a controversias respecto de las cuales nuestro Estado es extraño.

En un examen más detenido, tal vez esta doctrina no ha extraído necesariamente las consecuencias derivadas de las declaraciones de la Corte, que parecerían atribuir a la jurisprudencia del TEDH, no la eficacia de fuente del derecho que se reconoce a las sentencias interpretativas del Tribunal de Justicia, sino la de «derecho vivo» reconocida desde hace mucho tiempo a la jurisprudencia consolidada de la Corte de Casación, con la obligación de que el Tribunal haga del objeto del examen de la constitucionalidad la norma en el sentido «vivo», que obviamente, como ha sucedido varias veces, podrá ser declarado inconstitucional.

El quinto y último se refiere a la relación entre los dos Tribunales (constitucional y europeo) y consiste en identificar para ambos el mismo objetivo (mejor protección de los derechos fundamentales), pero reconocerles un papel diferente: el europeo proporciona la interpretación del CEDH con el fin de dar uniformidad, a nivel europeo, a la comprensión de los principios del CEDH, la Corte constitucional pretende determinar el posible conflicto entre la legislación nacional y el CEDH, si este último ofrece una garantía «al menos equivalente» y no entra en conflicto con nuestros principios constitucionales.

Por lo tanto, las «sentencias gemelas» abren una nueva fase para Italia, tanto, que casi se puede decir que para toda una serie de aspectos y problemas que veremos más adelante, es como si el CEDH hubiera entrado en vigor muchos años después, y ello puede explicar, aunque ciertamente no justificar, el error muy grave en el que cayó en una ocasión la suprema Corte de casación ${ }^{11}$.

11 La Corte de casación (ord 13 de junio de 2013, núm. 14903) al replantear una cuestión de constitucionalidad declarada infundada en 1995 por el Tribunal Constitucional, motiva la necesidad de que la Corte constitucional vuelva a la misma cuestión, sobre la base de algunos elementos de novedad normativa sobrevenidos respecto de la declaración de falta de fundamento. Un primer elemento de novedad se centra en la revisión constitucional del art. 111 de la Constitución (1999), mientras que un segundo se ve en la entrada en vigor para Italia del CEDH, con particular referencia al art. 6 del mismo. Acerca de la segunda «novedad», la casación cae en un error de fecha fatal, refiriéndose a la ratificación del CEDH a una ley de 4 de agosto de 1995 n. ${ }^{\circ}$ 848 (en lugar de, como se sabe, el 4 de agosto de 1955 , n. ${ }^{\circ} 848$ ).

No estaría mal si se tratara de lapsus calami, lo peor para la Suprema Corte es que en la motivación muestra cómo está realmente convencida de que el CEDH fue ratificado por Italia, y entró en vigor en nuestro país, en 1995. De hecho, la Corte Suprema recurre a este dato en el argumento para justificar la resolución de remisión y la nueva presentación de la cuestión a la Corte constitucional, es decir, la entrada en vigor del TEDH. De hecho, la Corte de casación señala que «ha intervenido la esperada normativa de orden constitucional y comunitario, lo que sin duda ha ratificado la objetividad e imparcialidad del juez entre los principios fundamentales de un juicio justo. (...) ciertamente fue implementada —en el período posterior a la sentencia $n^{\circ} 46$ de 1995 - esta nueva regulación específica, que consiste en la modificación del art. 111 de la Constitución, mediante la ley constitucional 2/99, así como por el art. 6 del Convenio de Estrasburgo ratificado con ley de 4 de agosto de 1995 n. ${ }^{\circ} 848$. De hecho, no se puede negar que las nuevas disposiciones, que se aprobaron con posterioridad al fallo $n .^{\circ} 46$ del Tribunal Constitucional en cuestión — han establecido y fortalecido de manera indiscutible (...) el principio de objetividad del juez «(cursivas añadidas). 
Después de 2007, debido al cambio jurisprudencial antes mencionado, se asiste al uso de las normas convencionales como parámetro interpuesto, en un número muy elevado de $\operatorname{casos}^{12}$ y la jurisprudencia del TEDH viene a fundamentar no solo el parámetro constitucional, sino también a actuar como motivación de la no manifiesta falta de fundamento de la cuestión de la constitucionalidad.

En consecuencia, hay muchos campos materiales que están particularmente afectados por la jurisprudencia europea, entre los cuales, por nombrar algunos, podemos mencionar el derecho de propiedad y la indemnización por expropiación, el proceso penal (derecho de defensa, garantía de contradicción, hipótesis de revisión del juicio penal, principio de ne bis in idem), de las leyes de interpretación auténtica y las leyes retroactivas; el matrimonio y reagrupamiento familiar; la reproducción médicamente asistida; o la regulación de la quiebra.

\section{LOS CRITERIOS DE INTERPRETACIÓN DEL CEDH: LA INTERPRETACIÓN EVOLUTIVA Y, EN PARTICULAR, LA INTERPRETACIÓN CONFORME AL CEDH Y SU RELACIÓN CON LA INTERPRETACIÓN CONSTITUCIONALMENTE CONFORME. EL PREDOMINIO AXIOLÓGICO DE LA CONSTITUCIÓN}

La última década se ha caracterizado en Italia por un interés cada vez mayor por el CEDH y por la jurisprudencia del TEDH, en el ámbito de la protección de los derechos fundamentales, y con ello, inevitablemente, también las relaciones con las disposiciones análogas contenidas en la Constitución en su aplicación práctica por jueces ordinarios y sobre todo por la Corte constitucional.

Son muchos, por tanto, los problemas que han surgido en los últimos años.

Queriendo tratar de resumir los aspectos que considero más interesantes y darles un orden, procederé distinguiéndolos en dos grandes ámbitos materiales: el primero, relativo a la posición de los jueces nacionales (ordinarios y constitucional) acerca de los criterios de interpretación del CEDH y la el valor que tiene para ellos la interpretación del mismo por el TEDH; a los problemas relacionados con la aplicación e inaplicación de las disposiciones convencionales; y a las cuestiones de constitucionalidad planteadas con referencia al CEDH como un parámetro interpuesto.

La segunda área tendrá como objeto los aspectos relacionados con la efectividad y ejecución de las decisiones del Tribunal de Justicia en el sistema legal italiano y el impacto de las mismas en los procesos judiciales.

Partiendo del primero y de los problemas relativos a la interpretación del CEDH, como en la Constitución y debido al contenido «constitucional» particular del CEDH, surge el problema de si los criterios y las técnicas interpretativas normalmente utilizados en relación con las leyes y las fuentes ordinarias son igualmente utilizables también para textos constitucionales.

12 Una cuidadosa investigación de campo, dirigida por Tania Groppi, reveló que en el período posterior a las sentencias gemelas y hasta el 30 de junio de 2016, 164 decisiones de la Corte constitucional han utilizado las disposiciones del CEDH como un parámetro para juicio de constitucionalidad de las leyes. GROPPI T., La jurisprudence de Strasbourg dans les décisions de la Cour constitutionnelle italienne, en Federalismi.it, 2016/21. 
La solución fue en gran parte en el sentido de que los criterios para interpretar la Constitución deben ser particulares y específicos, especialmente debido a que estos textos se expresan principalmente por principios en lugar de reglas y se caracterizan por la presencia de un «juez propio».

Así, se consideró que los criterios seguidos para la interpretación de la Constitución también pueden extenderse a la interpretación del CEDH y en particular la técnica de la «interpretación evolutiva», en el sentido de tener que tener en cuenta la evolución histórica, cultural y social después de la redacción de la Constitución.

Ciertamente, como se ha señalado ${ }^{13}$, el texto breve y sin antecedentes legales del $\mathrm{CEDH}$ deja poco espacio para interpretaciones literales o sistemáticas y el propósito de hacer efectivos los derechos reconocidos en la Convención implica necesariamente su actualización constante con respecto a los nuevos significados involucrados. desde el momento de su aprobación.

Esto ha planteado el problema de los límites dentro de los cuales se puede hacer una lectura evolutiva del texto del $\mathrm{CEDH}$, definidos, además de por los precedentes deducibles de la jurisprudencia del TEDH, y por el grado de consenso que una determinada interpretación del Convenio obtiene de los Estados miembros, en el ámbito del margen de apreciación que se les reconoce.

El hecho de haber reconocido que el CEDH puede operar como un parámetro interpuesto para el juicio de constitucionalidad de las leyes, inevitablemente le ha llevado al criterio de la interpretación conforme, desde el momento que el juez que se propone plantear la cuestión de la constitucionalidad en referencia a una disposición del CEDH debe necesariamente confrontar la interpretación de la misma, como resulta de la jurisprudencia del TEDH.

El juez, antes de proponer el asunto al Tribunal Constitucional $-\mathrm{y}$ comprobar la existencia de los requisitos de relevancia y de no manifiesta falta de fundamento previstos por la ley- debe verificar si las dudas de conformidad con el CEDH pueden superarse mediante una interpretación de la legislación nacional conforme al CEDH, extendiendo así a la interpretación convencionalmente conforme los mismos criterios desde hace tiempo elaborados con respecto a la necesaria interpretación conforme con la Constitución, que encuentra su base en el instrumento de las sentencias interpretativas de rechazo utilizadas por la Corte desde $1957^{14}$.

13 Repetto G., «Premesse ad uno studio sull'interpretazione evolutiva tra Costituzione e Convenzione europea dei diritti dell'uomo», en CASSETTI L. (ed.), Diritti, principi e garanzie sotto la lente dei giudici di Strasburgo, Napoli, Jovene, 2012, p. 21 y ss.

14 La declaración de falta de fundamento con indicación simultánea de la interpretación (la única) que podría haber salvado la ley de la declaración de inconstitucionalidad, mostraba de hecho que, entre las diversas interpretaciones posibles, tenía que ser seguida la que se ajusta a los principios constitucionales. La Corte ha ejercido esta función en una situación de monopolio y son muchas las razones por las cuales la situación de monopolio continuó durante muchos años. El avance se produjo a principios de los años noventa, inmediatamente después de la eliminación de la excesiva acumulación de trabajo y tal vez precisamente para evitar la creación de un nuevo retraso y alargar el proceso de toma de decisiones. De hecho, el Tribunal Constitucional comenzó a valorar positivamente la actividad interpretativa del juez ordinario hasta que llegó a la confirmación en 1996, luego se repitió y se aplicó un número infinito de veces. El Tribunal tuvo ocasión de hacer notar que «las leyes no se declaran inconstitucionales porque sea posible dar interpretaciones inconstitucionales (y algunos jueces quieran dársela), sino porque es imposible dar interpretaciones constitucionales». Dos años después de esta declaración se perfeccionó con la especificación de que el juez no sólo tenía la oportunidad de superar las dudas 
La consecuencia de la invitación a la verificación de la interpretación conforme fue, en algunos casos, la falta de homogeneidad de las soluciones seguidas por los jueces individuales, algunos de los cuales también llevaron a cabo interpretaciones muy atrevidas y «creativas» con respecto al dictado normativo. Por otro lado, en varios casos la propia Corte Constitucional ha brindado a los jueces un impulso a la «creatividad», ya que ella misma ha alcanzado, a través del uso de sentencias interpretativas, resultados a veces en abierto contraste con el texto de la ley interpretada.

Dado que en el ordenamiento italiano los poderes del Juez constitucional para interpretar la ley a la luz de la Constitución no son diferentes, ni mayores que los del juez ordinario (solo más autorizados), la actitud de la Corte constitucional no puede inducir a los jueces a comportamientos que son excesivamente «creativos».

El juez que debe plantear una cuestión de constitucionalidad con referencia a los parámetros convencionales y constitucionales, debe verificar preliminarmente la viabilidad de una interpretación conforme, sea con el CEDH, sea con la Constitución.

Si bien es cierto que se trata de una hipótesis que no es fácilmente verificable, sin embargo, puede ser el caso que para el juez se plantee el problema de cuál de los dos debe prevalecer en caso de conflicto.

La Corte constitucional, en relación con un caso muy controvertido y al que volveré más adelante, declaró a este respecto que no se discute que el juez sea competente para asignar a la disposición interna un significado más cercano al CEDH, siempre que no se revele totalmente excéntrico en comparación con la letra de la ley. Sin embargo, el deber del juez ordinario de interpretar el derecho interno de manera coherente con la Convención está, por supuesto, subordinado a la tarea prioritaria de adoptar una lectura conforme a la Constitución, ya que este modo de proceder refleja el predominio axiológico de la Constitución sobre el CEDH.

En la mayoría de los casos, según la Corte, la deseable convergencia de los operadores jurídicos y los tribunales constitucionales e internacionales hacia enfoques compartidos, en lo que respecta a la protección de los derechos humanos inviolables, ofrecerá una solución al caso concreto capaz de conciliar los principios que pueden inferirse de ambas fuentes. Pero, en las hipótesis extremas en que este camino parece estar bloqueado, no hay duda de que el juez primero debe observar la Carta republicana (sent. 49/2015).

Estas declaraciones de la Corte han sido criticadas por quienes vieron en ellas una visión piramidal y no axiológica de la relación entre las dos Cartas, hablando de un «patriotismo constitucional ingenuo y estéril» expresado por la Corte constitucional mediante la afirmación de la primacía cultural del nuestra Constitución y la ambición de la misma «para ser la Corte de las Cortes» ${ }^{15}$.

de constitucionalidad a través de una lectura de la disposición de forma constitucionalmente orientada, sino que tenía la obligación de demostrar que ha intentado tal posibilidad y motivar que no fue posible. Esto so pena de inadmisibilidad de la cuestión. La técnica de interpretación conforme ha producido una disminución significativa de las cuestiones planteadas en vía incidental, e incluso se ha considerado que se había producido un cambio en nuestro modelo de justicia constitucional por vía jurisprudencial, pasando de un modelo concentrado a un modelo de carácter difuso.

15 Ruggeri A., «Fissati nuovi paletti alla Consulta a riguardo del rilievo della Cedu in ambito interno», en Diritto penale contemporaneo, 2015/2. 


\section{EL SIGNIFICADO Y LA EFICACIA DE LA INTERPRETACIÓN DEL CEDH POR PARTE DEL TEDH: LA AFIRMACIÓN DE UN MONOPOLIO DEL TEDH Y LAS SUCESIVAS REDUCCIONES MEDIANTE LOS CRITERIOS DE LA TUTELA MÁS INTENSA, LA NECESARIA VALORACIÓN SISTÉMICA, EL CRITERIO SUSTANCIAL Y EL MARGEN DE APRECIACIÓN Y DE LA JURISPRUDENCIA CONSOLIDADA.}

En las «sentencias gemelas» antes mencionadas de 2007, la Corte constitucional declaró, entre otras cosas, el principio según el cual el CEDH en el proceso de constitucionalidad de las leyes, ya sea asumiendo el papel de parámetro interpuesto o de u objeto, debe asumirse con el significado que la jurisprudencia del TEDH ha dado a sus disposiciones. Esto se debe a que, entre las obligaciones internacionales asumidas por Italia con la firma del Tratado, está la de adaptar su legislación al CEDH, en el sentido que le atribuye «su» juez, a quien se le asigna una «función interpretativa eminente» ${ }^{16}$.

$\mathrm{Al}$ año siguiente, la Corte especificó las anteriores afirmaciones, en el sentido de un monopolio interpretativo por parte del TEDH, cuya interpretación debe por lo tanto considerarse vinculante para el juez (sent. 39/2008), alegando que la peculiaridad de las disposiciones del CEDH, dentro de la categoría de normas interpuestas «consiste en el sometimiento a la interpretación del Tribunal de Estrasburgo, al que los Estados contratantes, a excepción de un eventual control de constitucionalidad, están obligados a ajustarse».

Sobre la base de estas afirmaciones, se ha observado por la doctrina cómo el papel del juez nacional se ha reducido a la esfera aplicativa, «configurándose como un repetidor de la interpretación que es la que el (único) Tribunal Europeo debe proporcionar, por cuanto es a él al que se le atribuye institucionalmente la interpretación judicial del $\mathrm{CEDH}_{{ }^{17}} \mathrm{y}$ se ha utilizado la expresión «autoridad de cosa interpretada», para indicar la eficacia reconocida a la jurisprudencia del Tribunal Europeo.

Posteriormente, esta posición ha sido especificada y sustancialmente redimensionada por la Corte constitucional, que se ha reservado la valoración sobre la medida en que el CEDH, tal como lo interpreta el Tribunal de Estrasburgo, se integra en el ordenamiento constitucional italiano.

Esto ha sucedido también a través de la referencia al criterio «sustancial» de la tutela más intensa otorgada a los derechos fundamentales, en el sentido de que el cumplimiento de las obligaciones internacionales nunca puede conducir a una reducción en el nivel de protección, con la consecuencia de que, en el caso de contraste entre la legislación interna más garantista con respecto al CEDH, según lo interpretado por su juez, es la primera la que debe prevalecer y, en sentido diverso, no puede admitirse que un

16 En el escrito ya mencionado, el ponente de la resolución en cuestión, Silvestri, explicó cómo el adjetivo «eminente» referido a la jurisprudencia del TEDH había sido utilizado en el sentido de que en la interpretación del CEDH debe reconocerse un papel de absoluta importancia a esta jurisprudencia, pero el adjetivo no tiene el significado de «preeminente» o «vinculante», precisamente para dejar abierta la actividad de contextualización por parte del intérprete. SILVESTRI G., «Considerazioni conclusive», en Osservatorio sulle fonti, n. ${ }^{\circ}$ 1/2018 (www.osservatoriosullefonti.it).

17 Passaglia P. (Giovannetti T.), «La Corte ed i rapporti tra diritto interno e diritto sovranazionale», en Romboli R. (ed.), Aggiornamenti in tema di processo costituzionale (2008-2010), Torino, Giappichelli, 2011, p. 313 y ss. 
mayor nivel de protección, que pueda introducirse por esa vía, quede sustraído a los titulares de un derecho fundamental.

Por esta razón, «la comparación entre la protección convencional y la protección constitucional de los derechos fundamentales debe llevarse a cabo con el objetivo de la máxima expansión de las garantías, también a través del desarrollo de las potencialidades inherentes a las disposiciones constitucionales relativas a los mismos derechos» (sent. 317/2009).

El criterio axiológico-sustantivo mencionado anteriormente pone en evidencia la dificultad de identificar exactamente cuál de los dos sistemas de garantía es el que asegura el más alto nivel de protección, resultando así una inevitable indeterminación de la noción y, en consecuencia, un espacio para el intérprete para concretar la misma con respecto a los casos individuales.

Un redimensionamiento de la eficacia vinculante de la interpretación proporcionada por el TEDH se ha derivado de la afirmación de la Corte constitucional según la cual, en cualquier caso, es a ella a quien corresponde valorar el impacto de la interpretación proporcionada por el Tribunal Europeo en el orden interno. Esto se debe a que, si bien se requiere a este último que proteja los diferentes valores en juego de manera fragmentada, ya que está llamado a juzgar sobre la presunta violación de derechos individuales y específicos, la Corte constitucional realiza una evaluación sistémica y no aislada de todos los valores involucrados en la ley examinada y, por lo tanto, requiere una actividad de ponderación que solamente ella puede realizar adecuadamente (sent. 317/2009 y 264/2012)

De esta forma, viene a subrayarse una diferencia institucional en el funcionamiento de los dos Tribunales, que ofrece a la Corte constitucional la posibilidad de desvincularse de la interpretación ofrecida por el TEDH, siempre que la primera considere necesaria una actividad de equilibrio de naturaleza sistemática, sin poner en cuestión así la decisión del Tribunal Europeo con respecto al caso individual específico abordado.

En la misma línea, también debe incluirse la afirmación de que la Corte «tiene derecho a apreciar la jurisprudencia europea consolidada sobre la norma examinada, con el fin de respetar su esencia, pero con un margen de apreciación y de adecuación que le permita tener en cuenta las peculiaridades del ordenamiento jurídico en el que la norma convencional está destinada a insertarse» (sent. 236/2011).

La referencia al respeto «sustancial» de la interpretación del TEDH y el reconocimiento de «un margen de apreciación» permiten a la Corte constitucional hacer valer, con respecto a la jurisprudencia europea, las características del ordenamiento jurídico italiano y, por lo tanto, también seguir una solución que no se adhiere plenamente a la jurisprudencia de Estrasburgo.

La Corte constitucional subraya cómo el TEDH no afecta a las «razones imperativas de interés general» que pueden justificar las intervenciones del legislador nacional incluso de interpretación auténtica de leyes interpretativas anteriores y que el TEDH debe dejar a los Estados contratantes cuanto menos un parte de la tarea y la carga de identificarlos, ya que están en la mejor posición para llevarlo a cabo, tratándose, entre otros, de los intereses que están en la base del ejercicio del poder legislativo. Las decisiones en este ámbito implican, de hecho, una evaluación sistemática de los perfiles constitucionales, políticos, económicos, administrativos y sociales que el Convenio europeo deja a la competencia de los Estados contratantes (sent. 311/2009). 
Una posición decisiva a favor del margen interpretativo que debe reconocerse al tribunal nacional en relación con las interpretaciones del CEDH por parte del TEDH está representada por la decisión con la que la Corte constitucional ha puntualizado las condiciones en presencia de las cuales la interpretación del Tribunal Europeo puede considerarse vinculante para el juez.

La Corte constitucional ha observado que en las relaciones con el TEDH, los tribunales nacionales no deben considerarse receptores pasivos de una orden exegética dada en un primer pronunciamiento, sino - la lógica del enfrentamiento constructivo entre diferentes jueces y, por lo tanto, del carácter progresivo del derecho jurisprudencial, sin vértice- que impone que solo un «derecho consolidado», generado por la jurisprudencia europea, sea el que el juez interno está obligado a considerar al basar su proceso interpretativo, y que esto no ocurre frente a fallos que no son expresivos de una orientación que ha devenido definitiva, excepto en el caso de una «sentencia piloto» (sent. 49/2015).

La Corte constitucional también señala que, para poder considerar cierta interpretación proporcionada por el TEDH como «consolidada», el juez puede usar una serie de índices, que incluyen: la creatividad del principio establecido, en comparación con la estela tradicional de la jurisprudencia europea; cualquier punto de distinción, o incluso contraste, con respecto a otras resoluciones del Tribunal de Estrasburgo; la recurrencia de opiniones disidentes, especialmente si se apoyan de deducciones robustas; la circunstancia de que lo que se decide provenga de una simple sección y no haya recibido el respaldo de la Gran Sala; la duda de que, en el caso concreto, el juez europeo no haya estado en condiciones de apreciar las características peculiares del ordenamiento jurídico nacional, extendiendo los criterios de juicio elaborados hacia otros Estados miembros que, a la luz de esos rasgos se muestran, en cambio, poco adecuados para el caso italiano.

Frente a una jurisprudencia del TEDH que no puede considerarse consolidada o que no está contenida en una «sentencia piloto» en sentido estricto, no hay ninguna razón, según la Corte constitucional, que obligue al juez ordinario a compartir la línea interpretativa adoptada por el TEDH para decidir una controversia particular. Parece entonces que se entiende que no todas las interpretaciones expresadas por el juez de Estrasburgo poseen la misma eficacia y que solo unas pocas pueden considerarse vinculantes para el juez nacional.

Una autorizada magistrada constitucional (Marta Cartabia), que participó en la discusión y aprobación de la sentencia 49/2015, ha proporcionado una explicación del importante y muy discutido pronunciamiento. ${ }^{18}$ La conocida constitucionalista milanesa ha observado cómo las sentencias no pueden, a los efectos de la interpretación, ser consideradas como un texto legislativo: interpretar una sentencia no es lo mismo que interpretar una ley. Esto habría tardado en emerger ya que nuestra experiencia de civil law, a pesar del peso ahora adquirido por la jurisprudencia, ha impedido hasta ahora asimilar los criterios desarrollados por la experiencia del common law para evaluar el valor y la importancia de la precedente judicial. Es decir, qué significa la sumisión al

18 Cartabia M., «Corte costituzionale e Corte europea: alla ricerca di nuovi vettori giurisdizionali», en Padula C. (ed.), La Corte europea dei diritti dell'uomo. Quarto grado di giudizio o seconda Corte costituzionale?, Napoli, E.S., 2016, p. 229 y ss. 
precedente y el principio de stare decisis, cómo reconocer los obiter dicta, las reglas de distinguishing.

El propósito de la sentencia 49/2015, por lo tanto, habría sido abrir estos criterios con el fin de ayudar al juez a entender cuáles son las restricciones derivadas de las sentencias del TEDH, sin leer los pronunciamientos como si se tratara de leyes.

La decisión en cuestión ha sido objeto de muchas críticas por parte de la doctrina italiana, que ha resaltado cómo expresa una visión formalista y no axiológica de las relaciones entre los textos constitucionales y, sobre todo, las incertidumbres que pueden derivarse de la noción incierta de «jurisprudencia consolidada» y de los criterios indicados para su identificación. En particular, se señaló que el concepto recuerda de alguna manera al de «derecho vivo» y cómo la jurisprudencia del TEDH es una jurisprudencia casuística y, siendo claramente un caso siempre diferente del otro, no tendría sentido hablar de jurisprudencia consolidada o derecho vivo ${ }^{19}$ y cómo quedaría sin respuesta la cuestión de cuál es el valor y la eficacia de la jurisprudencia del TEDH que no pueda calificarse como una «sentencia piloto», ni como la jurisprudencia consolidada.

En este sentido, se ha observado que la jurisprudencia no consolidada termina siendo considerada un «derecho in progress y, por lo tanto, un no derecho ${ }^{20}$.

Para ilustrar el difícil uso de los criterios indicados por la Corte constitucional, se presentaron ejemplos de casos en los que una decisión importante de la Gran Sala tenía un alcance claramente innovador en comparación con la jurisprudencia anterior del TEDH (como en el caso reciente relacionado con el principio ne bis in idem), pero que seguramente no podría ser ignorado o no tomado en cuenta.

También en consideración a esto, se han avanzado interpretaciones de la sentencia 49/2015 para reducir los efectos negativos derivados de una aplicación literal de los principios expresados en ella.

Así, se ha propuesto negar carácter vinculante sólo a aquellas decisiones del TEDH que representen cambios abruptos y inmotivados en comparación con la orientación jurisprudencial anterior ${ }^{21} \mathrm{o}$ atribuir a la jurisprudencia del TEDH el efecto de obligar a todos los jueces y operadores jurídicos a «tener en consideración» ésta, pero con la posibilidad, sin embargo, de apartarse de ella en nombre de argumentos de carácter sustantivo que tiendan a lograr la solución más garantista en el caso concreto $^{22}$.

La respuesta del TEDH a la sentencia 49/2015 vino en buena medida de la STEDH de 27 de agosto de 2015, sobre el caso Parrillo, relativa a la posibilidad de calificar el juicio de inconstitucionalidad sobre las leyes en vía incidental como una sentencia necesaria para el agotamiento de recursos a nivel nacional y, por lo tanto, a los efectos de la admisibilidad del recurso individual. El TEDH reiteró a este respecto que «en el ordenamiento jurídico italiano, los litigantes no tienen derecho a presentar una solicitud directamente ante la Corte constitucional. Solo el juez que determina los méritos del caso

19 Sorrentr G., «Sul triplice rilievo di Corte cost, sent. 49/2015 che ridefinisce i rapporti fra ordinamento nazionale e Cedu e sulle prime reazioni di Strasburgo», en Forum di quaderni costituzionali, 7 dicembre 2015.

20 Contr R., La Cedu assediata?, en Consultaonline, 2015/1.

21 Sorrentr G., «Sul triplice rilievo di Corte cost, sent. 49/2015 che ridefinisce i rapporti fra ordinamento nazionale e Cedu e sulle prime reazioni di Strasburgo», en Forum di quaderni costituzionali, 7 dicembre 2015.

22 Rossi P., «L'interpretazione conforme alla giurisprudenza della Corte Edu: quale vincolo per il giudice italiano?», en Osservatorio sulle fonti, n. ${ }^{\circ} 1 / 2018$ (www.osservatoriosullefonti.it). 
tiene la posibilidad de dirigirse a la Corte constitucional, a instancia de una de las partes o de oficio. En consecuencia, este recurso no puede ser un remedio para el cual se requiere agotamiento en virtud del Convenio ${ }^{23}$.

En la opinión concurrente, cinco jueces de la Gran Sala señalaron que —después de las sentencias «gemelas» de 2007 que requieren que el juez ordinario, ante la imposibilidad de una interpretación conforme, devuelva la cuestión de constitucionalidad a la Corte constitucional de conformidad con el art. 117.1 de la Constitución - habrían estado a favor de considerar que en Italia se habría insituido un verdadero derecho de las partes para obtener el control de la constitucionalidad de una ley que no estaba en línea con la jurisprudencia de Estrasburgo. El punto de inflexión contenido en la sentencia 49/2015, sin embargo, volvió a eliminar esta conclusión, debido a la relativización de la eficacia vinculante de las sentencias del TEDH.

\section{LA INAPLICABILIDAD DE LA LEY CONTRARIA A LAS DISPOSICIONES DEL CEDH Y LA PROPOSICIÓN DE LA CUESTIÓN DE LEGITIMIDAD CONSTITUCIONAL EN VÍA INCIDENTAL. EL CONTROL DE LAS LEYES ANTERIORES A LA ENTRADA EN VIGOR DEL CEDH}

Con respecto al diferente fenómeno de la inaplicación por el juez ordinario de la ley nacional considerada contraria a las disposiciones del Convenio, se había verificado, como ya se mencionó, que algunos jueces decidieron aplicar al ordenamiento del CEDH las mismas reglas válidas para el ordenamiento de la Unión Europea, procediendo así a una «desaplicación» directa (o no aplicación) de la ley sin pasar por el control concentrado de la constitucionalidad de las leyes.

Esto justifica la declaración categórica contenida en las sentencias «gemelas» según las cuales el juez puede (y debe) en estos casos utilizar el CEDH como regla interpuesta para plantear ante la Corte constitucional una cuestión por presunta violación del art. 117.1 de la Constitución. Frente a la rotunda afirmación de la Corte, ciertamente no fue posible tener dudas al respecto, ni avanzar con diferentes interpretaciones.

A este respecto, constituye un hecho nuevo la aprobación del Tratado de Lisboa, que entró en vigor el 1 de diciembre de 2009 y, en particular, el art. 6.2 y 3 de la misma según el cual «la Unión se adhiere al CEDH»y «los derechos fundamentales garantizados por el Convenio (...) y que resultan de las tradiciones constitucionales comunes a los Estados miembros, forman parte del derecho de la Unión como principios generales».

En opinión de algunos, las innovaciones introducidas por el Tratado habrían llevado a un cambio en la ubicación de las disposiciones del CEDH en el sistema de fuentes, como para hacer que la mencionada concepción de las «reglas interpuestas» ahora esté desactualizada.

23 Esta afirmación ha sido discutida por Marta Cartabia en el texto que acabo de mencionar, sobre el supuesto que comparto de que el tribunal italiano no tiene el simple derecho de acudir, de oficio o a instancia de parte, a la Corte constitucional para plantear una cuestión de constitucionalidad relacionada con una ley. Una vez resuelta positivamente la existencia de los requisitos exigidos por la ley (pertinencia y no manifiesta de falta de fundamento) el juez tiene la obligación de proponer el asunto al juez constitucional y ciertamente no a una mera facultad. 
A la luz del nuevo texto del art. 6 del Tratado de la Unión Europea, estas disposiciones se habrían convertido en parte integrante del Derecho de la UE: con la consecuencia de que los tribunales ordinarios estarían facultados para no aplicar normas internas que se consideren incompatibles con las normas del Convenio, sin tener que activar el control de constitucionalidad.

También en este caso, la Corte constitucional ha sido muy clara al excluir tal efecto, en el sentido de que no se puede alegar ningún argumento a favor de la posibilidad de no aplicar una ley contraria a la Convención por estar prevista la adhesión de la Unión Europea al CEDH, por la sencilla razón de que la adhesión aún no se ha producido, por lo que, independientemente de cualquier otro remedio posible, la resolución del párrafo 2 del nuevo art. 6 del Tratado sigue siendo, en la actualidad, todavía improductivo de efectos. La identificación precisa de éstos obviamente dependerá de las modalidades específicas a través de las cuales se realice la adhesión en sí misma.

En cuanto a la referencia al CEDH contenida en el párrafo 3 del mismo art. 6 según el cual los derechos fundamentales garantizados por el Convenio «y resultantes de las tradiciones constitucionales comunes a los Estados miembros forman parte del Derecho de la Unión como principios generales»— se trata, según la Corte, de una disposición que retoma, como ya se ha mencionado, el esquema del anterior párrafo 2 del art. 6 del Tratado de la Unión Europea: evocando así una forma de protección preexistente al Tratado de Lisboa (sentencia 80/2011).

Si el juez ordinario tiene dudas sobre la compatibilidad de una disposición legislativa nacional con una disposición del CEDH y el texto de la ley no permite al juez superar la duda mediante una interpretación conforme con el Convenio, el juez está obligado a verificar primero si la previsión convencional es respetuosa con los principios constitucionales. De lo contrario, debe plantear la cuestión de la constitucionalidad de la ley de ratificación del $\mathrm{CEDH}$, en la parte en que introdujo en nuestra legislación una disposición que es contraria a la Constitución. Si se considera en cambio la conformidad de la CEDH con la Constitución, el juez está obligado a plantear una cuestión de constitucionalidad de la disposición legislativa por violación directa del Convenio e indirecta del art. 117.1 de la Constitución (teoría de la norma interpuesta).

Después de las sentencias «gemelas», muchas han sido, como ya se ha dicho, las cuestiones de constitucionalidad con las que los jueces ordinarios denunciaron una supuesta violación del CEDH, ya sea como único parámetro invocado para la declaración de inconstitucionalidad o, más a menudo, junto con otros parámetros constitucionales.

En muchos casos, la Corte constitucional evitó utilizar el parámetro convencional, enfrentando y evaluando la censura de la constitucionalidad solo con referencia a los «otros» parámetros constitucionales y luego juzgando que el vicio denunciado por un supuesto contraste con el CEDH era «absorbido».

Sin embargo, esto no excluye que, aun cuando no se haya manifestado explícitamente $^{24}$, la influencia de la jurisprudencia del TEDH en la solución de las cuestiones de

24 Así, por ejemplo, con respecto a la decisión de la Corte constitucional sobre el derecho del niño a conocer su identidad natural y el derecho absoluto y permanente al anonimato de la madre (véase STEDH de 25 de septiembre de 2012, caso Godelli y sent. Corte constitucional 278/2013) o sobre el derecho del niño al apellido materno (STEDH de 7 de enero de 2014, caso Cusan y Fazzo y sent. Corte constitucional 286/2016). 
constitucionalidad haya sido decisiva en muchas ocasiones para llevar a la Corte constitucional a un pronunciamiento de inconstitucionalidad.

Ha surgido un problema muy particular en relación al control de las leyes en vía incidental en referencia a la violación de las disposiciones del $\mathrm{CEDH}$, con respecto a la hipótesis de que el objeto de la cuestión de la constitucionalidad sean disposiciones legislativas anteriores a la entrada en vigor del CEDH.

Se trata de un problema análogo a lo que se planteó con respecto a las leyes anteriores a la Constitución cuando la Corte constitucional comenzó a funcionar, es decir, si debería, en estos casos, afirmar el principio de constitucionalidad o el de derogación, con la aplicación del principio temporal de la sucesión de leyes a lo largo del tiempo.

En este caso, la Corte constitucional, en su primera frase (1/1956), dejó abierta la posibilidad de ambas soluciones, reconociéndose a sí misma la posibilidad de verificar también la legitimidad de las leyes antes de la Constitución, pero sin excluir la posibilidad de que el juez aplicara el principio de derogación expresa.

Incluso para la presunta violación del CEDH, se planteó el problema de las leyes previas a la aprobación del CEDH y la Corte constitucional lo resolvió equiparando esta hipótesis con la de las leyes posteriores al CEDH (sentencia 39/2008).

\section{LOS CASOS MÁS EVIDENTES DE CONFLICTO ENTRE LA CORTE CONSTITUCIONAL Y EL TEDH: \\ A) EL TRATAMIENTO ECONÓMICO DEL PERSONAL DE ATA TRANSFERIDO DE LOS ENTES LOCALES AL ESTADO; \\ B) «LAS PENSIONES SUIZAS»; \\ C) LA CONFISCACIÓN URBANÍSTICA EN CASO DE SUBDIVISIÓN ILEGAL}

El tránsito de la fase en la que la Corte constitucional y el TEDH prácticamente se ignoraban, especialmente por la actitud adoptada por la primera, a la fase de «diálogo», ha determinado, junto con muchos elementos positivos, también el incremento de conflictos, más o menos fuertes, entre los dos Tribunales.

A los efectos de este artículo, vale la pena mencionar los tres casos que se pueden considerar como aquellos en los que el contraste se ha evidenciado de una manera más fuerte y casi disruptiva.

Los dos primeros tienen como objeto de las leyes de interpretación con las que el Parlamento proporcionaba, con efecto retroactivo, la interpretación correcta de una ley previa, con efectos incluso en los procesos pendientes. Fenómeno con respecto al cual la jurisprudencia constitucional se reveló a lo largo de los años bastante condescendiente con el legislador ${ }^{25}$.

25 La jurisprudencia constitucional sostenía que no era decisivo comprobar si la disposición impugnada tenía en realidad carácter efectivamente interpretativo (y por lo tanto fuera retroactiva) o era innovadora, con eficacia retroactiva, ya que en ambos casos se trataba de determinar si la retroactividad de la ley, cuya prohibición no ha sido declarada a nivel constitucional a excepción de en materia penal, encuentra una justificación adecuada en términos de razonabilidad y no entra en conflicto con otros valores e intereses protegidos por la Constitución. Por lo tanto, la norma censurada, cuando se ha considerado la expresión de la función de interpretación auténtica, no puede considerarse lesiva de los cánones constitucionales de razonabilidad y los principios generales de protección de la confianza legítima y de 
El primer caso se refiere a la transferencia del personal ATA de enseñanza (Administración, Técnicos y Auxiliares) de las autoridades locales al Estado, que había comportado para dicho colectivo unas condiciones económicas que eran más desventajosas que las disfrutadas anteriormente.

Tras los recursos judiciales, parcialmente estimados por la jurisdicción, el legislador había aprobado una ley de interpretación auténtica con la que había dado una interpretación favorable a los intereses económicos del Estado y perjudicial para los recurrentes.

En relación con esta ley, se planteó una cuestión de constitucionalidad por presunta violación de numerosos principios constitucionales, incluidos los de razonabilidad de la ley, derecho de defensa, confianza legítima del ciudadano, autonomía e independencia de los órganos jurisdiccionales.

La Corte constitucional declaró que la cuestión carecía de fundamento, refiriéndose a su jurisprudencia establecida en materia de leyes de interpretación auténtica (sentencia 234/2007).

Después de las resoluciones «gemelas», la cuestión volvió a presentarse, esta vez con referencia a la presunta violación del art. $6 \mathrm{CEDH}$, según la interpretación del TEDH y con referencia al art. 117.1 de la Constitución. La Corte constitucional también excluyó el defecto de constitucionalidad, al referirse a los «motivos imperativos de interés general» establecidos en la jurisprudencia europea para legitimar la intervención del legislador nacional.

El recurrente apeló entonces al TEDH, que en cambio se expresó en términos muy diferentes, declarando que las razones imperativas de interés general estaban indicadas por la necesidad de remediar un defecto técnico de la ley original y observando que «el objetivo declarado por el gobierno, es decir, la necesidad de llenar un vacío legal y eliminar la disparidad en el trato entre los trabajadores, en realidad tenía como objetivo preservar solo el interés económico del Estado, reduciendo el número de casos pendientes ante los tribunales italianos «.

Por lo tanto, la TEDH consideró que la intervención legislativa impugnada no estaba justificada por razones imperativas de interés público general y, por lo tanto, era contraria al art. 6.1 CEDH (STEDH de 7 de junio de 2011, caso Agrati).

La Corte constitucional respondió unos meses más tarde al citar el fallo mencionado por el TEDH y observando que hay margen para que el legislador intervenga retroactivamente, dado que «de lo contrario, si tal intervención se considerara una injerencia indebida con el propósito de influir en la resolución de una disputa, la regla misma estaría destinada a seguir siendo una mera enunciación, desprovista de significado concreto» (sent. 257/2011).

Por último, el TEDH sostuvo que el personal de ATA que se destinó a las funciones del Ministerio sin reconocimiento de antigüedad previa debía ser restituido a la misma situación que si la violación del Convenio no hubiera ocurrido (es decir, si el gobierno no hubiera requerido la interpretación del artículo 8 de la ley de 3 de mayo de 1999, n. ${ }^{\circ} 124$ de una manera diferente a la interpretación dada por la suprema Corte de Casación) y por

seguridad jurídica, en cuanto se limita a asignar a la disposición interpretada un significado reconocible como una de las posibles lecturas del texto original, sin que tal operación deba necesariamente estar encaminada a resolver contrastes jurisprudenciales, pudiendo así el legislador aclarar el significado de las normas cuando existan orientaciones homogéneas (sent. 74/2008). 
lo tanto tiene el derecho de recibir, a modo de satisfacción equitativa, la diferencia entre el tratamiento económico percibido y lo que hubiera obtenido en ausencia de la intervención de la «interpretación» (STEDH de 8 de noviembre de 2012, caso Agrati).

El segundo caso se refería a la regulación de las pensiones de los trabajadores italianos en el extranjero (específicamente en Suiza) y a una ley de interpretación auténtica a través de la cual se proporcionaba una lectura de la disposición interpretada en un sentido restrictivo y perjudicial para los destinatarios, con efecto retroactivo, también para los procesos pendientes.

La correspondiente cuestión de constitucionalidad había sido declarada infundada por la sentencia 172/2008, que consideró que la disposición impugnada asignaba a la disposición interpretada un significado ya deducible de la misma, garantizando también la racionalidad global del sistema de seguridad social, ya que evitaba que, frente a una pequeña contribución abonada en el país extranjero, se pudiera obtener los mismos beneficios que aquellos que habían trabajado exclusivamente en Italia y podían obtenerlos gracias a una contribución mucho más onerosa.

La Corte de Casación se adhirió a esta doctrina (8 de agosto de 2011, n. ${ }^{\circ}$ 17076) considerando que la disposición en cuestión constituía una norma efectiva y decididamente de interpretación auténtica destinada a aclarar el alcance de la disposición interpretada y, por lo tanto, no perjudicial para el principio del debido proceso de conformidad con el art. $6 \mathrm{CEDH}$, constituyendo un ejercicio legítimo de la función legislativa.

Posteriormente, el Tribunal de Estrasburgo, al pronunciarse sobre el mismo asunto como resultado de un recurso directo, consideró que la misma disposición había conducido a una violación de los derechos de los recurrentes, interviniendo decisivamente para impedir que el resultado del procedimiento en el que eran partes les fuese favorable (STEDH de 31 de mayo de 2011, caso Maggio).

Con referencia explícita a la mencionada decisión del TEDH, se propuso nuevamente la cuestión de constitucionalidad ante la Corte constitucional, esta vez invocando un parámetro diferente, es decir, el art. 117.1 de la Constitución, que impone a la ley (estatal y/o regional) el respeto de las obligaciones internacionales. La Corte constitucional, retomando su propia jurisprudencia, argumentó que el cumplimiento de las obligaciones internacionales nunca puede ser la causa de una reducción de la protección respecto de la ya establecida por el derecho interno, pero puede y debe ser una herramienta efectiva para ampliar dicha protección. Por esta razón, la comparación entre las diferentes regulaciones y por lo tanto entre los tribunales debe llevarse a cabo con el objetivo de la «máxima expansión de las garantías».

A tal fin, debe reconocerse a la Corte una función de ponderación entre los diferentes intereses constitucionalmente protegidos que entran en juego, ya que la protección de los mismos no puede lograrse mediante una valoración fraccionada de los derechos individuales (como puede ser en algunos casos la jurisprudencia de Estrasburgo), sino sistémica y, por lo tanto, valorando también el «margen de apreciación» nacional.

Esta es la piedra angular seguida por la Corte italiana para armonizar las dos jurisprudencias diferentes: una actividad de ponderación o equilibrio que en última instancia sólo puede corresponder al Juez constitucional nacional que está en mejores condiciones para llevar a cabo esta tarea, pero que no significa «primacía» del ordenamiento nacional, sino más precisamente «integración de las tutelas». 
Usando esta «clave» la Corte concluye que, en la actividad de ponderación con otros intereses constitucionalmente protegidos, respecto a la tutela del interés subyacente al parámetro especificado prevalece la protección de los intereses antagónicos de igual rango constitucional, claramente implicados en la regulación contenida en la disposición impugnada, en relación con la cual existen intereses generales preeminentes que justifican el uso de la legislación retroactiva. De hecho, los efectos de esta disposición se incluyen en el marco de un sistema de seguridad social que tiende a equiparar los recursos disponibles y las prestaciones otorgadas, también en cumplimiento de la restricción impuesta por el párrafo 4 del artículo 81 de la Constitución, y asegura una racionalidad general del sistema mismo, impidiendo alteraciones de la disponibilidad económica a expensas de algunos contribuyentes y en beneficio de otros, y asegurando así el cumplimiento de los principios de igualdad y solidaridad, que, por su carácter fundamental, ocupan una posición privilegiada en el equilibrio con otros valores constitucionales. En realidad, la ley se inspira en los principios de igualdad y proporcionalidad, ya que toma en cuenta el hecho de que las contribuciones pagadas en Suiza son cuatro veces más bajas que las pagadas en Italia y por lo tanto opera una reparación directa para conseguir que las contribuciones sean proporcionales a las prestaciones, nivelando así el trato a unos y otros, evitando las desigualdades y haciendo sostenible el equilibrio del sistema de seguridad social para garantizar a quienes se benefician de sus servicios (enviado 264/2012) ${ }^{26}$.

Posteriormente, el TEDH volvió a referirse a la cuestión de las «pensiones suizas» y volvió a considerar que la regulación italiana de interpretación auténtica contrasta, no solo con los principios del debido proceso (artículo 6.1 del CEDH), sino también con una valoración patrimonial en relación al sistema de cálculo de las pensiones que habría dado lugar a una carga excesiva para los demandantes sin un equilibrio adecuado de los intereses en juego (STEDH de 15 de abril de 2014, caso Stefanetti).

Fundamentándose sobre el único motivo del novum representado por esta STEDH (Stefanetti), se planteó una ulterior cuestión de constitucionalidad ante la Corte constitucional, que fue declarada inadmisible. La Corte observó en particular cómo la indicación de un umbral (fijo o proporcional) y un límite máximo de reducción de las «pensiones suizas» — con el fin de una reductio ad legitimatem de la disposición impugnada, que impida su impacto en las pensiones en la medida en que resulte lesivo para los preceptos convencionales y nacionales evocados-, así como la identificación del remedio, congruente y sostenible, capaz de salvaguardar el contenido esencial del derecho lesionado, son evidentemente necesarias pero obviamente presuponen la elección entre una pluralidad de soluciones sometidas, como tales, a la discreción del legislador.

La Corte, al declarar la inadmisibilidad de la cuestión, sostuvo sin embargo que «sería inaceptable la prolongación excesiva de la inercia legislativa sobre el grave problema denunciado por el Tribunal de Estrasburgo» (sent. 166/2017).

El tercer caso se refiere a la regulación italiana de la confiscación urbanística en caso de subdivisión ilegal.

26 La Corte constitucional encuentra una confirmación de la corrección de su argumentación en el hecho de que el TEDH en la citada sentencia Maggio (a diferencia de lo que sucedió con la sentencia Agrati un poco más adelante), condena a Italia por violación del arte. $6 \mathrm{CEDH}$, pero excluye la violación del art. 1 del Protocolo n. ${ }^{\circ} 1$, desde el punto de vista de la injerencia en el disfrute pacífico de los bienes a través de la reducción de la pensión. 
El TEDH tuvo la oportunidad de pronunciarse sobre la misma, entendiendo que en caso de absolución del delito de subdivisión ilegal, motivado por un error de prohibición, la confiscación de todos los terrenos subdivididos ilegalmente y los inmuebles construidos ilegalmente vulnera el art. 7 CEDH y el art. 1 del Protocolo 1 del mismo Convenio, siendo una sanción penal cuya aplicabilidad en el presente caso no estaba claramente prevista por la ley y además desproporcionada al objetivo de protección ambiental perseguido (STEDH de 20 de enero de 2009, caso Soc. Sud Fondi).

A ello siguió una sentencia de inadmisibilidad de la Corte constitucional de la cuestión de la legitimidad constitucional del art. 44, segundo párrafo, del D. P. R. de 6 de junio de 2001 n. 380 , en la parte en que se requiere que el juez penal, en presencia de una subdivisión ilegal comprobada, disponga de la confiscación de los terrenos y obras construidas ilegalmente, independientemente del juicio de responsabilidad y en perjuicio de personas no relacionadas con los hechos. La inadmisibilidad se basa en la insuficiente motivación en cuanto a la relevancia y por no haber demostrado el juez la imposibilidad de una interpretación de la disposición impugnada de conformidad con la normativa internacional (referida al CEDH) tal y como se interpreta por el TEDH. En esa ocasión, la Corte constitucional especificó que «sólo si la adaptación interpretativa, que parece necesaria, es imposible o si el eventual "derecho vivo" que se forme al respecto genera dudas sobre su legitimidad constitucional, esta Corte puede ser llamada a enfrentar el problema de la presunta inconstitucionalidad de las disposiciones de la ley».

En la jurisprudencia de la Corte de Casación prevalecía la interpretación según la cual se puede ordenar la confiscación de los terrenos incluso en presencia de una causa extintiva del delito, como la prescripción, siempre que se establezca la existencia de una subdivisión abusiva desde un punto de vista objetivo y subjetivo, en el contexto de un proceso que asegure el principio contradictorio y la adecuada comparecencia de los interesados, y que verificara la existencia de perfiles al menos de culpabilidad, bajo la apariencia de imprudencia, negligencia y culpa in vigilando de los sujetos en contra de los cuales se impone dicha medida (Sentencia de Casación de 4 de febrero de 2013, n. ${ }^{\circ}$ 17066).

Posteriormente, el TEDH intervino nuevamente y declaró la violación del art. 7 CEDH y del art. 1 Protocolo. n. ${ }^{\circ} 1$ en el caso en el que el tribunal penal solicitó la confiscación de los terrenos subdivididos ilegalmente y de los inmuebles construidos sobre ellos con la sentencia de sobreseimiento por extinción del delito debido a la prescripción (STEDH de 29 de octubre de 2013, caso Varvara).

Haciendo referencia a este último fallo, se elevó una nueva cuestión de constitucionalidad ante la Corte constitucional, con referencia al art. 117.1 de la Constitución. La Corte consideró la cuestión inadmisible refiriéndose al principio, anteriormente mencionado y discutido, de la necesaria «consolidación» de la jurisprudencia de TEDH para que la misma puede ser considerada como vinculante para el juez.

La Corte constitucional concluye que los tribunales a quibus eran muy conscientes de que no se trataba de una jurisprudencia consolidada del Tribunal Europeo, y por tanto, no sólo no estaban obligados a extrapolar de la STEDH Varvara el principio de derecho del cual se han servido para motivar las cuestiones planteadas, sino que deberían haberse atenido a una lectura contraria a la misma. Esta lectura es de hecho compatible con el texto de la sentencia y con los detalles del caso, más acorde con la lógica tradicional de la 
jurisprudencia europea, y aún así respetuosa con el principio constitucional de subsidiariedad en materia penal, así como con la discrecionalidad legislativa en política criminal, que incluye la opción (interna) de la naturaleza administrativa de la sanción.

\section{LA EFICACIA Y APLICACIÓN EN ITALIA DE LAS SENTENCIAS DEL TEDH. LA STEDH COMO FUENTE DEL DERECHO: LOS CASOS DE RESTITUCIÓN DE LOS ACTOS POR «NOVUM» SUPERVENIENS. LOS OBSTÁCULOS PROCESALES: LA SUPERACIÓN DE LA COSA JUZGADA PENAL (EL CASO DORIGO) Y EL PROBLEMA ANÁLOGO EN MATERIA CIVIL Y ADMINISTRATIVA}

Abordamos ahora el segundo conjunto de los problemas indicados, es decir, las cuestiones relacionadas con la eficacia y la aplicación de las sentencias del TEDH en el ordenamiento jurídico italiano.

No es necesario subrayar cómo el rol y la naturaleza del Tribunal Europeo han evolucionado de una matriz esencialmente internacional a una que podríamos llamar constitucional.

En la primera fase, prevaleció el aspecto relativo a la protección de los derechos individuales, la naturaleza meramente declarativa de la decisión, con la obligación estricta y específica para los Estados de la reparación equitativa, cuando así se disponía, habida cuenta de una mayor discrecionalidad de éstos para cumplir la obligación de eliminar las causas de la violación.

Posteriormente, la actividad de TEDH parecía estar más proyectada hacia la protección del interés general y el respeto del derecho objetivo, a través de una integración, en la práctica, de lo previsto literalmente en el art. $41 \mathrm{CEDH}$, moviéndose más y más a menudo más allá de la satisfacción equitativa, a través de la indicación de medidas específicas, tales como introducir cambios estructurales en el ordenamiento jurídico nacional.

Por lo tanto, son precisamente las sentencias las que indican la necesidad de restitutio in integrum y de cambios en el ordenamiento las que han planteado los mayores problemas para su ejecución en el ordenamiento italiano.

Sobre la posibilidad de calificar la sentencia del TEDH como fuente de derecho, puede ser útil recordar dos decisiones de la Corte constitucional, en las cuales se devolvieron a los jueces a quibus las actuaciones relativas a las cuestiones de constitucionalidad planteadas sobre la base de un cambio en la jurisprudencia del TEDH.

En el primer caso se trató la cuestión de la constitucionalidad de la ley sobre la reproducción médicamente asistida, en la parte en que excluía la posibilidad de recurrir a la práctica de la inseminación heteróloga.

El TEDH con una primera resolución de una de sus secciones (Sección I, 1 de abril de 2010, caso $\mathrm{SH}$ ), consideró que dicha exclusión era contraria a los principios expresados por el CEDH y, sobre la base de esa decisión, algunos jueces italianos plantearon la cuestión de la constitucionalidad de la ley 40/2004 ante la Corte constitucional.

En espera de la decisión, se había emitido una segunda resolución sobre el mismo caso, esta vez por la Gran Sala, que por el contrario consideró que la legalidad o no de la inseminación heteróloga formaba parte del «margen de apreciación» que debe reconocerse en cada Estado (STEDH de 3 de noviembre de 2011). 
La Corte constitucional (ord. 150/2012), recordando la importancia que debe reconocerse en las sentencias del TEDH, calificó la sentencia sobrevenida como un «novum que afecta directamente la cuestión de la legitimidad constitucional, tal como se ha propuesto» y por lo tanto devolvió las actuaciones a los tribunales a quibus para un reexamen de la relevancia, justificándolo también con la afirmación de que, de lo contrario, no habiendo podido los jueces a quibus dialogar sobre la base de la sentencia sobrevenida, se habría alterado el esquema del juicio de las leyes en vía incidental.

En esta ocasión, la Corte utilizó deliberadamente el término «novum» superveniens, casi como algo que surge entre el «ius» y el «factum», no obstante atribuyendo, básicamente, a la sentencia de la Gran Sala el efecto hasta ahora reconocido por el ius superveniens ${ }^{27}$

En el segundo caso, la cuestión de la constitucionalidad tenía como objeto la regulación legal que no excluye la posibilidad de establecer una sentencia penal respecto de los mismos hechos para los cuales ya se ha impuesto definitivamente una sanción administrativa, al término de un procedimiento administrativo. El juez denunció la violación del principio de ne bis in idem, refiriéndose al art. 4, protocolo 7, del CEDH, como norma interpuesta, de conformidad con el art. 117.1 de la Constitución.

En particular, la autoridad judicial basó las dudas de constitucionalidad en la interpretación de la disposición convencional resultante de la jurisprudencia del TEDH, según la cual una sanción puede considerarse esencialmente delictiva o penal por su carácter represivo o preventivo y subrayó cómo esta jurisprudencia tuvo como objeto hipótesis completamente asimilables al objeto del proceso a quo (sanciones administrativas por evasión fiscal).

En el período comprendido entre la emisión de la resolución de remisión y la decisión de la Corte constitucional se produjo un cambio de jurisprudencia inesperado por parte de la Gran Sala del TEDH, que, al tiempo que confirmaba el carácter sustancialmente penal de la sanción administrativa aflictiva, superó la lectura exclusivamente procesal del principio de ne bis in idem (imposibilidad de iniciar el proceso penal en presencia de una sanción administrativa definitiva) para pasar a una noción sustancial del mismo, invitando a los jueces a evaluar, en este caso, el tipo de conexión sustancial y temporal existente entre los dos procedimientos. El TEDH de hecho ha excluido la violación del artículo 4, Protocolo 7, CEDH cuando entre el proceso administrativo y el proceso penal es evidente una conexión suficientemente estrecha en el nivel sustantivo y temporal (STEDH de 15 de noviembre de 2016, casos A y B c. Noruega).

Al devolver las actuaciones al tribunal a quo, la Corte constitucional habla de un «cambio jurisprudencial» que podría producir efectos en la relación entre los procedimientos administrativo y penal y concluye que «el cambio en el significado de la normativa interpuesta, sobrevenido a la orden de remisión, como resultado de un fallo de la Gran Sala del Tribunal de Estrasburgo que expresa el «derecho vivo» europeo, implica la

27 La decisión de devolver las actuaciones al tribunal a quo es un tipo de pronunciamiento no previsto por la ley, sino creado por la jurisprudencia de la Corte constitucional, que en consecuencia ha tenido diferentes aplicaciones a lo largo del tiempo.

En los últimos años, la devolución se utiliza casi exclusivamente para la hipótesis de un cambio normativo (ius superveniens) que va a afectar a la ley objeto de la cuestión de constitucionalidad, para solicitar al juez una nueva evaluación de relevancia o no manifiesta falta de fundamento de la cuestión planteada.

La jurisprudencia constitucional ha equiparado la modificación normativa, a los fines de la devolución, las sentencias de inconstitucionalidad y las sentencias interpretativas del Tribunal de Justicia de la Unión Europea. 
devolución de las actuaciones al tribunal nacional, a los efectos de una nueva evaluación sobre la relevancia de la cuestión de la legitimidad constitucional» (sent. 43/2018) ${ }^{28}$.

En estos casos, la Corte constitucional utiliza expresiones como «novum», «nueva regla», «cambio de sentido» y no la de «ius superveniens», que es la utilizada para las sentencias del Tribunal de Justicia de la UE, para evitar expresiones demasiado exigentes, pero no se puede descartar que el tratamiento reservado para las decisiones del TEDH se equipare significativamente, en cuanto a los efectos, a una fuente del derecho ${ }^{29}$.

Los obstáculos, dados los límites que encuentra el TEDH en su actividad como garante del $\mathrm{CEDH}$, han sido principalmente de dos tipos:

a) de naturaleza procesal;

b) en razón a la naturaleza legislativa del acto que debe suprimirse.

Con respecto a lo primero, me propongo referirme principalmente al tema la cosa juzgada y al valor, también de significación constitucional, que se le reconoce a la misma para la garantía de seguridad jurídica.

Dado el carácter subsidiario del recurso ante TEDH y por lo tanto la necesidad de haber agotado previamente todos los recursos que el ordenamiento pone a disposición de los ciudadanos para la protección de sus derechos, es natural que la resolución del TEDH puede estar en conflicto con la cosa juzgada que mientras tanto se ha producido a nivel nacional. De ahí la necesidad de conciliar el respeto a la cosa juzgada, y los valores que expresa, con la obligación de ejecutar las sentencias del TEDH de conformidad con el art. $46 \mathrm{CEDH}$.

Este aspecto se ha hecho aún más evidente, desde el momento que se ha ido prestando más atención a la ejecución de las sentencias del TEDH a causa del requerimiento cada vez más frecuente de obligaciones de restitución y de intervenciones normativas o paranormativas destinadas a proponer la superación de la cosa juzgada o controlar el cumplimiento de las decisiones de Estrasburgo.

Con respecto a la cosa juzgada penal, la experiencia italiana está vinculada al conocido caso Dorigo, por lo que vale la pena volver a analizarlo y, con él, explicar cómo se ha resuelto el problema en Italia.

28 En la primera hipótesis se trataba del mismo caso, decidido en primera instancia por una sección, y luego, a petición del gobierno italiano, por la Gran Sala; mientras que en la segunda, frente a una jurisprudencia consolidada, incluso de la Gran Sala, sobreviene un cambio claro de la misma mediante un pronunciamiento de la Gran Sala.

29 Si es clara la diferencia en el régimen del derecho originario y derivado de la Unión Europea (aplicación directa, primacía, etc.) respecto al del CEDH (fuente definida por la Corte como de nivel infra constitucional), el tema específico del relieve que un pronunciamiento jurisdiccional puede asumir para la devolución de las actuaciones parece estar relacionado principalmente con el carácter más o menos vinculante para el juez de la interpretación expresada en la sentencia. En otras palabras, lo que asume importancia es el posible «cambio de significado de la ley» objeto de la pregunta, que induce al juez constitucional a solicitar, como sucede en el caso de ius superveniens, un nuevo examen por parte del juez a quo.

Parece bastante razonable, más allá de su calificación, cómo una interpretación de la norma objeto de la cuestión o incluso del parámetro, directo o interpuesto, que resulta para el juez absolutamente vinculante, si la misma ocurre después de la resolución del orden de remisión, justifique una devolución de las actuaciones. En este caso, de hecho - a diferencia de un hecho que incide sobre la relevancia del específico proceso principal, pero no cambia la cuestión relativa a un acto normativo general y abstracto-, la sentencia sobrevenida va a afectar al contenido del acto normativo del mismo modo que un cambio normativo (de interpretación auténtica). 
La Comisión Europea (9 de septiembre de 1998) había encontrado en el proceso penal contra el Sr. Dorigo una violación de la garantía del principio de contradicción y por lo tanto declaró la violación del art. 6 de la Convención.

En consecuencia, la Corte de Casación consideró que la fuerza de cosa juzgada penal era «inaplicable», con la consecuencia de que la persona condenada ya no tendría que expiar la parte restante de la pena (sent. el 25 de enero de 2007, n. ${ }^{\circ} 2800$ ).

Posteriormente se planteó, en referencia también al art. $6 \mathrm{CEDH}$, una cuestión de constitucionalidad que sin embargo fue declarada infundada por la Corte constitucional (sent. 129/2008), que al hacerlo consideró que «no podía eximirse de dirigir al legislador una invitación urgente a tomar las medidas consideradas más idóneas para permitir que el ordenamiento se adecue a las sentencias del TEDH que han encontrado, en los procesos penales, violaciones de los principios consagrados en el art. 6 del $\mathrm{CEDH} »^{30}$.

Siguiendo esta sentencia, los jueces ordinarios, y en particular la Corte de Casación, han procedido en varios supuestos a buscar una solución «justa» mediante interpretaciones conformes bastante atrevidas, cuando no a través de una «desaplicación» pura y dura de la ley procesal.

La cuestión de la constitucionalidad fue nuevamente elevada a la Corte constitucional, esta vez con referencia específica al art. 117.1 de la Constitución y el art. 46 CEDH.

También en consideración de la inercia del legislador a su «invitación urgente», esta vez la Corte llega a una declaración de inconstitucionalidad de la norma procesal, valorando así que la obligación de cumplir con las decisiones del TEDH debe prevalecer sobre el principio, también importante, de cosa juzgada. En particular, declara la inconstitucionalidad del art. 630 del Código procesal penal, en la parte en la que no contemplaba un caso de revisión «diferente», de entre los previamente regulados, específicamente dirigido a permitir la reapertura del proceso, cuando sea necesario, de conformidad con el art. 46, 1. CEDH, para cumplir con un fallo final del TEDH (sentencia 113/2011).

La Corte atribuye a los jueces la tarea de evaluar también cómo las causas de la falta de equidad del juicio reveladas por el Tribunal Europeo deben traducirse tanto en vicios de los actos procesales como en el derecho interno, adoptando en la nueva sentencia todas las medidas consiguientes para eliminarlos, al tiempo que subraya que el legislador obviamente sigue siendo libre de regular con una normativa diferente —incluso

30 La Corte Constitucional observa que la cuestión de la legitimidad constitucional surge de la ausencia —en el sistema procesal penal — de un remedio apropiado, destinado a poner en práctica la obligación del Estado de cumplir (incluso a través de una eventual renovación del proceso) las sentencias definitivas del TEDH, en el caso en que se ha verificado la violación del Convenio o sus Protocolos.

La Corte recuerda cómo el Comité de Ministros y la Asamblea del Consejo de Europa, estigmatizaron con reiteradas resoluciones, resoluciones provisionales y recomendaciones — precisamente en referencia a la historia del Sr. Dorigo - la inercia del Estado italiano al adoptar las medidas correctivas adecuadas y cómo el Comité de Ministros — después de las «advertencias» anteriores_ expresamente deploró «el hecho de que, más de seis años después de la declaración de infracción en este caso, las autoridades italianas no han tomado ninguna medida para cancelar en la medida de lo posible las consecuencias de la violación (restitutio in integrum) y que no se han implementado soluciones alternativas, como la concesión del indulto presidencial «. De la misma manera, la Asamblea Parlamentaria del Consejo de Europa en la Resolución n. ${ }^{\circ} 1516$ (2006) —aprobada el 2 de octubre de 2006, sobre la implementación de las sentencias del TEDH - deploró el hecho de que «en Italia y, en cierta medida, en Turquía, la ley aún no prevé la reapertura de los procesos penales en los que el Tribunal había constatado violaciones del CEDH y estos dos Estados no han tomado otras medidas para restablecer el derecho de los demandantes a un juicio justo a pesar de las solicitudes apremiantes y reiteradas del Comité de Ministros y la Asamblea». 
desplazada por la introducción de un instituto autónomo y distinto- el mecanismo para adaptar los pronunciamientos definitivos del Tribunal de Estrasburgo, así como dictar normas sobre aspectos específicos del mismo, sobre los que este Tribunal no podría intervenir, ya que implican decisiones discrecionales (como, por ejemplo, la previsión de un plazo de caducidad para la presentación de la solicitud de reapertura del juicio, a partir de la sentencia definitiva del Tribunal Europeo).

La decisión arriba mencionada fue unánimemente apreciada por la doctrina, que señaló que la Corte no se había limitado a «importar un producto» del sistema convencional, sino que ha «eliminado una barrera aduanera» entre ambos sistemas (Cartabia) o cómo la elasticidad de la cosa juzgada puede entenderse referida al meta-principio de la maximización de la tutela, lo que permite a la Constitución italiana dar lo mejor de sî́1.

Refiriéndose a la misma decisión, se planteó una nueva cuestión de constitucionalidad mediante la cual se pidió a la Corte constitucional que ampliara la conclusión alcanzada con respecto al juicio penal a los procesos civiles y administrativos. La Corte (sentencia 123/2017) no estimó la cuestión, señalando que de la jurisprudencia del TEDH no surge, en materias diversas a la penal, un deber general de adoptar la medida de restitución de la reapertura del proceso y cómo se trata en materia civil y administrativa el problema del respeto al principio contradictorio, toda vez que la sentencia ante el TEDH se produce en contradicción entre el recurrente y el Estado autor de la presunta violación, con la presencia sólo eventualmente de las demás partes que participaron en el proceso interno ${ }^{32}$.

\section{SIGUE: LOS OBSTÁCULOS DE CARÁCTER NORMATIVO: LA PRESENCIA DE UNA LEY QUE HA DETERMINADO LA VIOLACIÓN DEL CEDH O IMPEDITIVA DEL RESULTADO REQUERIDO POR EL TEDH. EL DIFERENTE ROL DE LOS JUECES, LA CORTE CONSTITUCIONAL Y EL LEGISLADOR. LA EJECUCIÓN DE LA SENTENCIA EN FAVOR DE LA PARTE VENCEDORA EN ESTRASBURGO Y LA DIFERENTE POSICIÓN DE LOS SUJETOS QUE SE ENCUENTRAN EN LA MISMA SITUACIÓN SUSTANCIAL}

El segundo tipo de obstáculo para la ejecución de una sentencia del TEDH que requiere cambios estructurales con el fin de la restitutio in integrum puede estar representado por la presencia de una norma nacional a la que se pueda atribuir el incumplimiento del CEDH o que en cualquier caso contraste con consecución del resultado requerido por el TEDH.

31 RugGeri A., «Corte europea dei diritti dell'uomo e giudici nazionali, alla luce della più recente giurisprudenza costituzionale (tendenze e prospettive)», en Osservatorio costituzionale Aic, 1/2018, 5 febbraio 2018.

$32 \mathrm{La}$ Corte constitucional destaca que las personas que participaron en el proceso nacional no deben ser notificadas del recurso ante el TEDH y cómo se remite (Artículo 36.2 del TEDH) a la evaluación discrecional del Presidente del mismo Tribunal para «invitar» a cada persona interesada presentar observaciones por escrito o participar en audiencias».

La Corte también señala que «una apertura sistemática del proceso convencional a terceros —al cambiar las fuentes convencionales o en virtud de su interpretación adaptativa por el TEDH— facilitaría el trabajo del legislador nacional», en el sentido de superar la cosa juzgada también en asuntos civiles y administrativos. 
En este sentido, parece necesario distinguir si se trata de ejecutar la sentencia del TEDH en favor de la parte vencedora en el proceso convencional o de un sujeto diferente que se encuentra en la misma situación o similar. Y en este segundo caso podríamos diferenciar, aún más, entre los que tienen un proceso pendiente en Estrasburgo (que podría beneficiarse de una sentencia piloto), los sujetos que todavía no han recurrido y aquellos que pertenecen al mismo Estado condenado por la STDEH o a incluso otro Estado.

En el primer caso (parte vencedora en Estrasburgo) el Estado sin duda debe, de conformidad con el art. $46 \mathrm{CEDH}$, implementar la sentencia de condena del TEDH, pero frente a una legislación interna contrastante cabe preguntarse quién puede (o debe) intervenir (juez, Corte constitucional, legislador) y qué poderes se le pueden reconocer al respecto.

La tesis, en mi opinión, más convincente es la que considera, en este caso, que el juez está legitimado para ejecutar la sentencia europea, ya que la presencia de la misma viene a determinar un nuevo elemento, a nivel normativo, que viene a integrar la «regla» que el juez debe aplicar al caso específico.

La regla general y abstracta de la ley, a la cual el juez está constitucionalmente sujeto, reemplaza una regla específica derivada de la sentencia y del art. 46 CEDH, y al criterio jerárquico le sustituye el de la especialidad ${ }^{33}$.

Teniendo en cuenta lo anterior, el juez no procede a una no aplicación, sino a aplicar una nueva regla y esto, como lo señaló Repetto ${ }^{34}$, puede ocurrir en presencia de cuatro supuestos:

a) que el recurrente sea la parte vencedora en Estrasburgo, pudiendo sólo él beneficiarse del arte. $46 \mathrm{CEDH}$;

b) que exista, en la legislación nacional, un recurso interno que permita a la parte llevar su caso ante un juez;

c) que la sentencia del TEDH sea autoaplicativa, o sea, que el resultado pueda lograrse sin la necesidad de una regulación detallada y no plantee una pluralidad de posibles soluciones;

d) que la «regla» convencional no esté en conflicto con los principios constitucionales.

Si no es la parte vencedora en Estrasburgo, no hay remedio ante un juez, la sentencia no es autoaplicativa o la regla está en conflicto con los principios constitucionales, el juez debe plantear una cuestión de constitucionalidad y solo la intervención de la Corte constitucional puede superar el obstáculo representado por una ley. Por todo ello, la doctrina habla de la existencia de una «doble vía» para la ejecución de sentencias del TEDH.

En este sentido, como se ha dicho, no podríamos utilizar la noción de no aplicación, que no se reconoce al juez con respecto al sistema del CEDH, ni tampoco la de

33 Padula C., «La Corte Edu e i giudici comuni, nella prospettiva della recente giurisprudenza costituzionale», en PAdula C. (ed.), La Corte europea dei diritti dell'uomo. Quarto grado di giudizio o seconda Corte costituzionale?, Napoli, E.S., 2016, p.159 y ss.

34 Repetto G., «L'effetto di vincolo delle sentenze della Corte europea dei diritti dell'uomo nel diritto interno: dalla riserva di bilanciamento al "doppio binario"», en Diritto pubblico, 2014, p. 1075 y ss. 
interpretación conforme ${ }^{35}$. De hecho, no parece posible distinguir la noción de interpretación conforme y los límites que ésta encuentra en particular con respecto al texto normativo, dependiendo de si es utilizada por el juez «a monte» (antes de la sentencia del Tribunal) o «a valle «(para dar ejecución a la misma), en el sentido de que en el segundo momento se debe considerar incrementada la carga preceptiva de la interpretación conforme, de tal modo que es posible ir mucho más allá que cuando se lleva a cabo la misma operación en el primer momento.

Por el contrario, sobre la base de lo que acabamos de decir, parece correcto el planteamiento ${ }^{36}$ según el cual la sentencia del TEDH introduciría un «novum» normativo que hasta ese momento los tribunales nacionales no habrían podido tomar en consideración y que les permite completar la protección.

Pasando ahora al caso de sujetos que se encuentran en la misma situación que el recurrente pero que no han recurrido o aún no han obtenido un pronunciamiento del TEDH, y excluyendo el supuesto de una sentencia de condena contra un Estado distinto, la situación dentro del Estado condenado, cuando se trata de una decisión que se refiere a una situación estructural, es bien diferente.

En Italia, se ha dado este supuesto y se llegó a una conclusión, que podemos exponer a través de la reconstrucción del famoso caso Scoppola.

El TEDH había condenado a Italia por violación del art. 7.1 CEDH (STDEH el 17 de septiembre de 2009, caso Scoppola), afirmando que el Estado italiano estaba obligado a garantizar que la pena de cadena perpetua — ergastolo — impuesta al demandante fuera reemplazada por otra que no excediera la pena de prisión de treinta años.

La decisión había sido ejecutada por la Corte de Casación (sent. el 28 de abril de 2010, n. $^{\circ}$ 16507), que había procedido a anular el fallo anterior, que había adquirido firmeza, considerando «inaplicable» la fuerza de cosa juzgada «por el nuevo hecho» de la sentencia europea, dada la absoluta claridad de la misma y la obligación que se deduce del art. $46 \mathrm{CEDH}$ para el Estado italiano.

Ante la solicitud de aplicación de la misma solución a otras partes que se encontraban en la misma situación que Scoppola, pero que no habían recurrido ante el Tribunal de Estrasburgo, la Corte de Casación había procedido en algunos casos a extender la misma solución, mientras que el Pleno de la misma decidió plantear la cuestión de la constitucionalidad (ord. 10 de septiembre de 2012), encontrando una restricción insuperable a la extensión antes mencionada en el tenor literal de la ley, que claramente no permitía tal resultado.

La Corte constitucional (sent. 210/2013) consideró correcta la aplicación directa por parte de la Corte de Casación con respecto a Scoppola y que la sentencia del TEDH debe aplicarse también a otros casos que presenten las mismas características, sin necesidad de un recurso específico ante el TEDH.

Con respecto a las formas en que se puede lograr este resultado, la Corte observa que existe una «diferencia radical» entre los destinatarios de una decisión del TEDH y los que, por otro lado, no se encuentran en la misma situación sustancial. En este segundo caso, dado que el juez no puede proceder a la no aplicación de la legislación nacional, está

35 Malfatti E., «L'interpretazione conforme nel «seguito» alle sentenze di condanna della Corte di Strasburgo», en Scritti in onore di Gaetano Silvestri, Torino, Giappichelli, 2016, p. 1288 y ss.

36 Ibidem. 
obligado a plantear la cuestión de la constitucionalidad para permitir que sea eliminada por el Tribunal Constitucional ${ }^{37}$.

\section{UNA NOTA PARA REFLEXIONAR SOBRE ALGUNAS HIPÓTESIS FUTURAS: \\ A) LA ADHESIÓN DE LA UNIÓN EUROPEA AL CEDH; B) LA ENTRADA EN VIGOR DE LA PREJUDICIALIDAD CONVENCIONAL A QUE SE REFIERE EL PROTOCOLO XVI; C) LAS POSIBLES REFORMAS DEL SISTEMA ITALIANO DE JUSTICIA CONSTITUCIONAL PARA UN DIÁLOGO MÁS FRUCTIIFERO CON LOS TRIBUNALES EUROPEOS: EL RECURSO INDIVIDUAL DIRECTO Y LA TRANSICIÓN A UN SISTEMA «DUAL»}

Para concluir me gustaría desarrollar algunas consideraciones, de manera sintética y a modo de apuntes sobre los que se podría reflexionar en otra ocasión, a cerca de las perspectivas futuras del tema abordado en este escrito, obviamente siempre con referencia particular a la situación italiana.

Quisiera referirme en particular a tres aspectos:

a) la previsión de la adhesión a la UE del CEDH;

b) la muy reciente entrada en vigor del Protocolo XVI del CEDH;

c) las posibles reformas del sistema de justicia constitucional italiano para adaptarlo mejor a las relaciones que se han establecido en los últimos años con el TEDH (y también con el Tribunal de Justicia de la UE).

Sobre el primer aspecto, como sabemos, se encuentra aún a la espera de implementación la previsión del art. 6.2 del Tratado de funcionamiento de la UE que estipula que la UE se adhiera al CEDH, precisando que esto no implicará cambios en las competencias definidas en los Tratados.

Sin perjuicio del papel y las funciones ejercidas por el Tribunal de Justicia, parece preverse que el TEDH debería asumir la competencia para juzgar el respeto del Convenio no solo por los Estados, sino también por la Unión, con la consecuencia de tener también que interpretar la legislación de la UE y juzgar sobre las sentencias del Tribunal de Justicia por presunta violación del CEDH. Sobre este punto es conocida la posición claramente negativa expresada por este último en el Dictamen del 18 de diciembre de 2014, en el que se solicitaba, entre otras cosas, que para cualquier procedimiento ante el TEDH que tuviera como objeto el derecho comunitario, se debería transmitir a los órganos de la Unión Europea una información completa y sistemática, a fin de verificar si el Tribunal

37 Estos mismos principios fueron posteriormente confirmados por la Corte constitucional, con respecto a la normativa nacional sobre reproducción médicamente asistida, en relación con el posible diagnóstico de implantación a parejas no estériles que son portadoras sanas de enfermedades genéticamente transmisibles. Se trata de la ejecución de la STEDH de 28 de agosto de 2012, caso de Costa y Pavan, y la consiguiente sentencia de la Corte constitucional $96 / 2015$. 
de Justicia se habría pronunciado sobre la interpretación correcta o no, y en caso de no ser así, activar el procedimiento correspondiente. De lo contrario, la jurisdicción del Tribunal de Justicia se vería perjudicada.

Ciertamente, ya existen bastantes razones para creer que, si alguna vez se implementara la disposición, las relaciones entre los dos tribunales europeos, con repercusiones inevitables también en los tribunales nacionales, tendrían que encontrar un nuevo equilibrio, debiendo, entre otras cosas, conciliar el planteamiento de la cuestión prejudicial ante el Tribunal de Justicia con el carácter subsidiario del recurso ante el TEDH ${ }^{38}$.

Además de la relación «entre Tribunales», casi con toda certeza surgirá una relación entre «Cartas», es decir, entre el CEDH y la Carta de los Derechos Fundamentales de la Unión Europea.

Se ha observado ${ }^{39}$ que las disposiciones de los Tratados de adhesión de la UE se colocan al mismo nivel de los principios generales del Derecho de la Unión Europea, por tanto, en una posición intermedia entre los Tratados originarios y el derecho derivado. En consecuencia, la Carta de Derechos, a la que se reconoce formalmente el mismo valor que los Tratados, se ubicaría en una posición formalmente superior al CEDH, que se coloca en el nivel de principios generales.

En cuanto a los problemas que pudieran surgir de dicha adhesión, uno sin duda estaría vinculado a la posibilidad de proceder a una no aplicación directa de la legislación nacional, en contraste con el CEDH, como resultado de la «comunitarización» de la misma, con la consiguiente extensión del mismo régimen. Como ya he mencionado, la Corte constitucional (sentencia 80/2011) ha excluido que, sobre la base del art. 6.2 del Tratado, los jueces puedan proceder a la no aplicación, pero la motivación se basó principalmente en la falta de implementación de esta disposición, por lo que la cuestión se volvería ciertamente a proponer una vez que se implementara.

El segundo aspecto, en cambio, se refiere a un procedimiento no solo previsto sino también muy recientemente implementado, es decir, la posibilidad de solicitar al TEDH opiniones consultivas sobre cuestiones de principio relativas a la interpretación o aplicación de los derechos y libertades definidos por el CEDH o sus protocolos ${ }^{40}$

Existen muchas expectativas en este instrumento para mejorar las relaciones entre los tribunales, especialmente para evitar recurrir al TEDH o prevenir condenas, por ejemplo, en relación con vulneraciones de naturaleza estructural, dictando una especie de sentencias piloto tempranas, como ha sostenido el Presidente del TEDH, Raimondi, en la entrevista concedida a Diletta Tega ${ }^{41}$

38 Randazzo A., La tutela dei diritti fondamentali tra Cedu e Costituzione, Milano, Giuffrè, 2017.

39 CARDONE A., «Corte europea dei diritti dell'uomo, giudici comuni e disapplicazione della legge: appunti per la comprensione delle trasformazioni della forma di stato", en PAdula C. (ed.), La Corte europea dei diritti dell'uomo. Quarto grado di giudizio o seconda Corte costituzionale?, Napoli, E.S., 2016, p. 65 y ss.

40 El Protocolo XVI del CEDH, de hecho, tras la ratificación de Francia, entró en vigor el 1 de agosto de 2018. De conformidad con el art. 8 de lo mismo eran necesarias, de hecho, diez ratificaciones ahora alcanzadas con diez países que han depositado la ratificación, a saber, Albania, Armenia, Estonia, Finlandia, Francia, Georgia, Lituania, San Marino, Eslovenia y Ucrania.

Italia ha firmado el protocolo, pero aún no ha depositado el instrumento de ratificación.

41 El presidente Raimondi revela que en el TEDH que hay jueces favorables y contrarios a las disposiciones del Protocolo XVI, especialmente por temor a un aumento en la carga de trabajo. Raimondi se declara a favor porque lo considera un instrumento que puede aumentar las posibilidades de diálogo con los tribunales nacionales y porque, en este contexto, el TEDH puede expresar principios generales, mientras que en su actividad normal sólo decide 
A pesar de que el objeto de los dictámenes sean «cuestiones de principio», parece indudable que la institución debe considerarse como una cuestión prejudicial y, por lo tanto, concreta, dado que la opinión puede solicitarse «solo en el ámbito de una causa pendiente ante» la autoridad requirente y que ésta «debe motivar la solicitud de opinión y presentar los elementos pertinentes inherentes al contexto jurídico y fáctico de la causa pendiente».

Dada la naturaleza prejudicial, será inevitable que se plantee el problema de colocarla en relación con las otras dos resoluciones prejudiciales que ya operan en el ordenamiento jurídico italiano, o sea, la de carácter constitucional ante la Corte constitucional y la comunitaria ante el Tribunal de Justicia ${ }^{42}$.

En el proyecto de ley presentado por el gobierno italiano para la ratificación del Protocolo XVI, la autoridad solicitante solo tiene la facultad (y no la obligación) de suspender el proceso pendiente a la espera del dictamen. La previsión suscita cierta perplejidad, ya que la solicitud se hace con respecto a un procedimiento específico en curso, por lo que parece paradójico que, después de solicitar la opinión, el juez proceda sin esperar la respuesta del TEDH, con el riesgo de decidir de manera diferente con respecto a lo que después será el dictamen. Un aspecto decisivo será la identificación de las «autoridades judiciales» con derecho a solicitar el dictamen, que se ha dejado a la elección de cada una de las partes contratantes, y por tanto a la opción discrecional de poder político.

En el proyecto de ley del gobierno italiano entre las autoridades judiciales no figura, increíblemente, la Corte constitucional, lo que limitaría seriamente la finalidad perseguida por los dictámenes preventivos a que se refiere el Protocolo XVI ${ }^{43}$.

La naturaleza sólo facultativa de la solicitud de dictamen y, sobre todo, el carácter no vinculante del mismo, son elementos que deben examinarse a través de la aplicación práctica de la institución, pudiéndose también verificar que estas características asuman después en realidad una dimensión exactamente opuesta a la que resulta de la letra del Protocolo.

Sobre el tercer aspecto, relativo a las posibles reformas para ajustar el sistema italiano de justicia constitucional a las exigencias derivadas de la relación con los otros tribunales, un conocido constitucionalista italiano (Amato) se ha preguntado si son realmente útiles tres ordenamientos diversos, con tres tribunales diferentes para garantizar su observancia, y cuál es su función.

A esta pregunta podemos dar una respuesta positiva si la relación entre los diferentes tribunales y los diferentes jueces es la de diálogo e integración recíproca, manteniendo como objetivo, un poco compartido por todos, la máxima protección de los

sobre casos específicos. TEGA D., «Corte di Strasburgo e stati: dialoghi non sempre facili. Intervista di Diletta Tega a Guido Raimondi», en Quaderni costituzionali, 2014, p. 463 y ss.

42 En este sentido, recientemente la Corte constitucional procedió a una importante integración de su jurisprudencia con respecto a la denominada doble prejudicialidad (constitucional y comunitaria). Hasta entonces, de hecho, la jurisprudencia constitucional era absolutamente clara al requerir la prioridad del recurso a Luxemburgo, pero con la sentencia 267/2017 ha estimado que, cuando se toma en consideración una disposición de la Carta de los Derechos Fundamentales de la Unión Europea, tiene prioridad la Corte constitucional.

43 De hecho, las solicitudes de un dictamen consultivo pueden ser instadas por las siguientes autoridades judiciales: Corte de Casación, Consejo de Estado, Tribunal de Cuentas y Consejo Administrativo de Justicia para la Región de Sicilia. La exclusión de la Corte constitucional ha sido casi unánimemente criticada, así, por ejemplo, fue considerada «sorprendente» por Groppi y «deplorable» por Cartabia. 
derechos fundamentales ${ }^{44}$. No sería así si, en cambio, se tuvieran que verificar solapamientos innecesarios y, por lo tanto, contrastes inevitables.

En este sentido, Marta Cartabia ha hablado de «crisis», respecto a la situación de solapamiento entre la Corte constitucional y el TEDH, poniendo acertadamente de relieve la necesidad de definir un orden en las relaciones entre los dos Tribunales. Excluida por casi todo el mundo la posibilidad de recurrir al criterio jerárquico y por lo tanto de disponer una sistematización jerárquica de los diversos tribunales, el criterio a seguir que parece más correcto es el de establecer un orden de acceso e intervención en la materia de los diferentes protagonistas, evitando definir lo más importante en base al hecho de quién habla el último.

En este sentido, podríamos considerar, con Cartabia, que es preferible que el Juez Constitucional sea el primero en actuar, porque está más cerca de la cuestión y porque opera a través de un instrumento (el juicio en vía incidental) que une la visión objetiva con la subjetiva y por tanto viene a colocarse en la mejor posición.

Sería muy útil la previsión de un instrumento adecuado que facilite el diálogo y la integración entre las diferentes jurisprudencias (incluyendo ciertamente el nuevo procedimiento referido en el protocolo XVI), para la realización de esa interpretación «circular» sostenida hace tiempo por Antonio Ruggeri, según la cual no se puede establecer un orden jerárquico entre las diferentes interpretaciones conformes, debiendo cada una apreciar cuánto más o mejor puede dar cada Carta (y por lo tanto cada Tribunal).

El largo tiempo transcurrido desde que se tomaron en Italia las decisiones sobre el modelo de justicia constitucional que opera actualmente y, más recientemente, los nuevos y diferentes problemas planteados por la tutela supranacional y la necesidad de introducir instrumentos adecuados para conciliar mejor los diversos niveles de protección, llevan a cuestionar la necesidad u oportunidad de proceder a una integración del sistema actual.

Un impulso podría derivar de la jurisprudencia del TEDH mencionada anteriormente con respecto a la introducción en Italia de un recurso individual directo, que pueda ser calificado como uno de los recursos que necesariamente deben interponerse antes de acudir ante el TEDH conforme al principio de subsidiariedad, y con el fin de permitir que la Corte constitucional se pronuncie antes que el TEDH.

En el debate que hubo en Italia sobre la introducción de un recurso directo, personalmente todavía considero que una valoración de los costes y beneficios, en su conjunto, se resuelve en la dirección opuesta a la introducción del recurso directo, al menos en el sentido del amparo constitucional español ${ }^{45}$

Por último, sería posible pensar, como lo he propuesto en otra ocasión ${ }^{46}$, en una transformación del modelo italiano «mixto» a otro «dual», que se caracteriza por la coexistencia de un control difuso y un control concentrado, coordinados entre sí de manera distinta. Esta es la experiencia actual, en diversas formas, en Portugal, Brasil y Perú,

44 Giuliano Amato, en el escrito mencionado en el texto, señala que no es necesario elegir entre la derecho europeo y las tradiciones nacionales de derechos, pero debemos entender que más allá de cierto límite la uniformidad no puede ser, pero más allá de un cierto límite las diferencias destruyen nuestra unidad, por lo tanto, es necesario encontrar un equilibrio entre las dos instancias.

45 Carrillo M., Romboli R., La reforma del recurso de amparo, Fundacion Coloquio juridico europeo, Madrid, 2012.

46 Romboli R., «I differenti livelli di protezione dei diritti: un invito a ripensare i modelli», en Forum $d i$ Quaderni costituzionali, Rassegna n. ${ }^{\circ} 3 / 2014$. 
donde un modelo originariamente difuso fue posteriormente «agregado» a otro concentrado, sin eliminar, sin embargo, el primero.

En nuestro caso, la experiencia evidentemente debería seguir el camino inverso, es decir, «agregar» el modelo difuso al concentrado que existe ahora.

Ante un supuesto conflicto entre una ley o acto con fuerza de ley nacional y la Constitución, el CEDH o la legislación de la UE, la posición del juez siempre debe ser la misma, planteando así la alternativa entre desaplicación o no aplicación de la ley y la proposición de la cuestión de constitucionalidad ante la Corte constitucional. De esta forma, esta última asumiría un papel fundamental de conexión a nivel interno respecto de la interpretación de la Constitución y de la ley a la luz de ella y, sobre todo, de interlocutor activo y privilegiado con los tribunales europeos, con respecto a los cuales podría hacer valer con más eficacia las exigencias y posiciones nacionales emergentes, en lo que respecta a las tradiciones constitucionales y el margen de apreciación del Estado.

TITLE: The influence of the ECHR and the European Court's case law on the italian costitutional system

ABSTRACT: The essay focuses on the level of influence that the ECHR and the European Court's case law exercise on the Italian constitutional system, revealing how important it has been to collocate the Convention in the sources of law's system and to recognize that it has the same level of ordinary statutes. It is particularly underlined how, in Italy, the ECHR influence started wit the "twins judgments" of the Constitutional Court in 2007, which helped the use of the ECHR as a parameter, of the constitutional legitimacy of statutes. This created a much closer contact with the European Court and, consequently, many possible occasions for conflicts, which are widely analyzed. Particular attention is dedicated to the importance of the European Court's interpretation of the ECHR and to the effectiveness of the condemnations of the States by the European Court, highlighting two obstacles: the ones depending on procedure law, with special reference to the value of judgments, and the ones depending on substantial law, with special reference to the existence of a national statute. In this second case, the solution is different depending if we consider the situation of a subject that is part of the trial or the one of a subject that hasn't been apart of it. The essay concludes with some short considerations about some future or present events, such as the entry into force of Protocol number 16 of the ECHR and a possible reform of the Italian constitutional justice system.

RESUMEN: El ensayo examina la influencia del CEDH y de la jurisprudencia del TEDH en el ordenamiento constitucional italiano, señalando la considerable importancia que tuvo, en ese ámbito, la ubicación de la Convención en el sistema de fuentes y la atribución a la misma del nivel de ley ordinaria. En particular, se evidencia cómo en Italia la influencia del Convenio ha comenzado a partir de las denominadas «sentencias gemelas» de 2007 de la Corte Constitucional, pues la interpretación del Constitucional permitió que se utilizara el CEDH como parámetro en los procesos de control de constitucionalidad de las leyes. Eso dio lugar a un contacto más estrecho con el TEDH y, por tanto, también a posibles casos de conflicto, que se analizan detalladamente. Se presta especial atención a la eficacia de la interpretación del CEDH por el TEDH y al tema de la eficacia de las sentencias que condenan a los Estados, indicando dos tipos de obstáculos: los de carácter procesal, es decir, el valor de la cosa juzgada y los de carácter normativo, a saber, la presencia de una ley nacional. En este segundo caso, se subraya como la solución es diferente dependiendo de si se consideran los efectos de las sentencias del TEDH respecto de la parte que resultó victoriosa en el proceso ante el TEDH o de otros sujetos que están en la misma condición sustancial, pero que no estaban presentes en el proceso que terminó con la condena. El escrito finaliza con unas breves observaciones sobre algunos acontecimientos recientes o futuros, como la entrada en vigor del Protocolo XVI del CEDH, la adhesión de la Unión Europea al CEDH y una eventual reforma del modelo de justicia constitucional italiano.

KEY WORDS: ECHR. Italian constitutional system.

PALABRAS CLAVE: CEDH. Sistema constitucional italiano.

FECHA DE RECEPCIÓN: 10.07.2018 FECHA DE ACEPTACIÓN: 13.09.2018 